\author{
Recommendations
}

\title{
Test methods for on-site corrosion rate measurement of steel reinforcement in concrete by means of the polarization resistance method
}

\author{
Prepared by C. Andrade and C. Alonso with contributions from J. Gulikers, R. Polder, \\ R. Cigna, Ø. Vennesland, M. Salta, A. Raharinaivo and B. Elsener
}

The text presented hereafter is a draft for general consideration. Comments should be sent to the TC Chairlady: Dr. Carmen Andrade, CSIC - Instituto de Ciencias de la Construccion "Eduardo Torroja", Serrano Galvache s/n - Aptdo 19.002, 28033 Madrid, Spain; Tel.: +34 130204 40; Fax: +34 130207 00; Email: andrade@ietcc.csic.es, by 30 May 2005.

TC Membership - Chairlady: C. Andrade, Spain; Secretary: B. Elsener, Switzerland/taly; Members: C. Alonso, Spain; R. Cigna, Italy; J. Galland, France; J. Gulikers, The Netherlands; U. Nürnberger, Gernany; R. Polder, The Netherlands; V. Pollet, Belgium, M. Salta, Portugal; $\varnothing$. Vennesland, Norway; R. Weydert, Germany/Luxemburg; Corresponding members: C. Page, UK; C. Stevenson, South Africa.

\section{SCOPE}

This Recommendation covers the description of nondestructive electrochemical test methods for the estimation in large size concrete structures of the instantaneous corrosion current density, $\mathrm{i}_{\text {corr }}$, expressed in $\mu \mathrm{A} / \mathrm{cm}^{2}$, by means of the so-called Polarization Resistance technique, $\mathrm{R}_{\mathrm{p}}$, in order to assess the condition of embedded steel reinforcement related to its corrosion.

The values of $i_{\text {corr, }}$ can be used to assess the rate of degradation of concrete structures affected by reinforcement corrosion. However, they cannot give information on the actual loss in steel cross section which, at present, only can be assessed by means of direct visual observation.

Values of the free corrosion potential or half-cell potential, $E_{\text {corr }}[\mathrm{V}]$, of the embedded reinforcing steel and of the electrical concrete resistance, $R_{e}[\Omega]$, are obtained as preliminary steps of the $R_{p}$ measurements. Values of the concrete resistivity, $\rho[\Omega \mathrm{m}]$, can be calculated from $R_{e}$ values providing the geometrical arrangement of the electrodes enables this calculation.

Both parameters, $E_{\text {corr }}$ and $R_{e}$ (or $\rho$ ) may be used to complement the reliability of the $i_{\text {corr }}$ measurements.

\section{SIGNIFICANCE AND USE}

The test methods described in the present Recommendation are suitable for on-site condition assessment of steel reinforced concrete structures.

The methods can be applied regardless of the thickness of concrete cover and the rebar size or detailing. However, when the bars are electrically connected, only the corrosion of the closer layer of reinforcements facing the counter electrode, CE, can be measured. This closer reinforcement layer practically shields the penetration of the polarizing current to deeper lying reinforcements. When rebars are electrically isolated, the steel bar connected to the instrument will be measured irrespective of its depth (depths higher than $1 \mathrm{~m}$ have been tested).

The test methods can be used at any time during the service life of the structure, and in any kind of climate, providing the temperature is higher than $0^{\circ} \mathrm{C}$. A very dry concrete surface of $\rho>1000 \Omega \mathrm{m}$ makes the measurement difficult. Some prewetting of the concrete surface is always necessary.

The $\mathrm{I}_{\text {corr }}$ results obtained by the test methods can be used for one of the following purposes: 
1) To assess the present corrosion condition of the reinforcement, that is, to discriminate between corroding and non-corroding (passivated) zones.

2) To evaluate the effectivity of a repair work.

3) To calculate the loss in rebar cross section by means of integration of $I_{\text {corr }}$ during the propagation period (providing the initiation time is known). This calculation enables the $I_{\text {corr }}$ values to be implemented into structural models in order to assess the further development of the structural performance with respect to cover cracking, loss of bond and loss of load-bearing capacity.

The corrosion current values in addition to the measurements of the corrosion potential, $E_{\text {corr }}$ and of the concrete resistivity, $\rho$, may be complemented by other data from the concrete: rebar diameter, chloride profile, depth of carbonation, porosity, temperature, cover thickness, exposure conditions, crack pattern, etc, in order to help in the evaluation and prediction of future performance of the structure.

The corrosion current values must be interpreted by specialists or skilled engineers experienced in the field of corrosion testing and structural evaluation.

\section{DEFINITIONS}

\subsection{Polarization Resistance, $\mathbf{R}_{\mathbf{p}}$}

The Polarization Resistance, $R_{p}$, of a reinforcement embedded in concrete is define applied voltage $\Delta \mathrm{E}$ (shift in poter step of current $\Delta \mathrm{I}$, when the (about $20-50 \mathrm{mV}$ ) from its free com
It can also be defined as the slope an also be defined as the slope
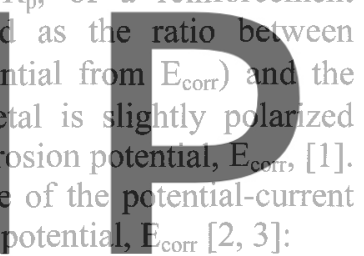

$\Delta E$

\subsection{Instantaneous corrosion current density, $\mathbf{i}_{\text {corr }}$}

The instantaneous corrosion current density, $i_{\text {corr }}$, is obtained by dividing a constant, $B$, by the $R_{p}$ value [2]:

$i_{\text {corr }}=\frac{B}{R_{p}}$

where $R_{p}$ is expressed in $\Omega . \mathrm{cm}^{2}$ and $\mathrm{B}$ in $\mathrm{V}$ is a constant resulting from a combination of the anodic and cathodic Tafel slopes:

$$
\mathrm{B}=\frac{\mathrm{b}_{\mathrm{a}} \cdot \mathrm{b}_{\mathrm{c}}}{2.303 \cdot\left(\mathrm{b}_{\mathrm{a}}+\mathrm{b}_{\mathrm{c}}\right)}
$$

Its value for steel reinforcement embedded in concrete has been determined by means of calibration against mass loss measurements [1]. For on-site measurements the recommended value of $B=26 \mathrm{mV}$

The standard units of $i_{\text {corr }}$ are $\mu \mathrm{A} / \mathrm{cm}^{2}$ (also $\mathrm{mA} / \mathrm{m}^{2}$ is currently used).

Non uniform corrosion current, $I_{\text {corr }}$

A non uniform corrosion current, $\mathrm{I}_{\text {corrs }}$ (written in capital I instead of i) may also be obtained through expression (2) [1, 5]. It is used when corrosion attack is expected to be localized.

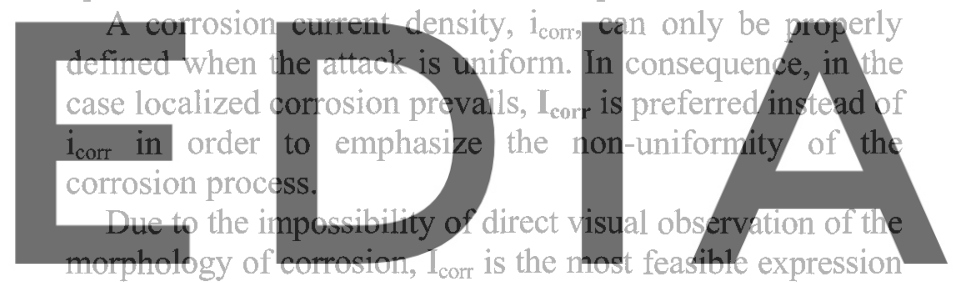

of the corrosion current when measuring in concrete.

\section{donktgapostar varsion without the watermark}

The corrosion rate or corrosion velocity, $V_{\text {corr }}$ represents the volumetric loss of metal by unit of area and unit of time. In the present Recommendation it is expressed in $\mathrm{mm} / \mathrm{year}$, although other units may also be used.

$\mathbf{V}_{\text {corr }}$ expressed in $\mathrm{mm}$ /year is obtained from the corrosion current, (either $i_{\text {corr }}$ or $I_{\text {corr }}$ ) in $\mu \mathrm{A} / \mathrm{cm}^{2}$ through Faraday's law and the density of the metal. For the steel, 1 $\mu \mathrm{A} / \mathrm{cm}^{2}$ is equivalent to a corrosion rate of $0.0116 \mathrm{~mm} /$ year for uniform attack.

$\mathrm{V}_{\text {corr }}(\mathrm{mm} / \mathrm{y})=0.0116 \mathrm{i}_{\text {corr }}\left(\mu \mathrm{A} / \mathrm{cm}^{2}\right)$

\section{GENERAL CONSIDERATIONS ON $R_{p}$ TECHNIQUE RELEVANT FOR ON-SITE MEASUREMENTS}

\subsection{Basic aspects}

The calculation of the corrosion rate from Polarization Resistance, $R_{p}$, technique is well established [2, 3, 6-9]. The application to the measurement of the corrosion of steel reinforcement started about 1973, [1, 5, 10-23] and the agreement between gravimetrically determined weight loss 


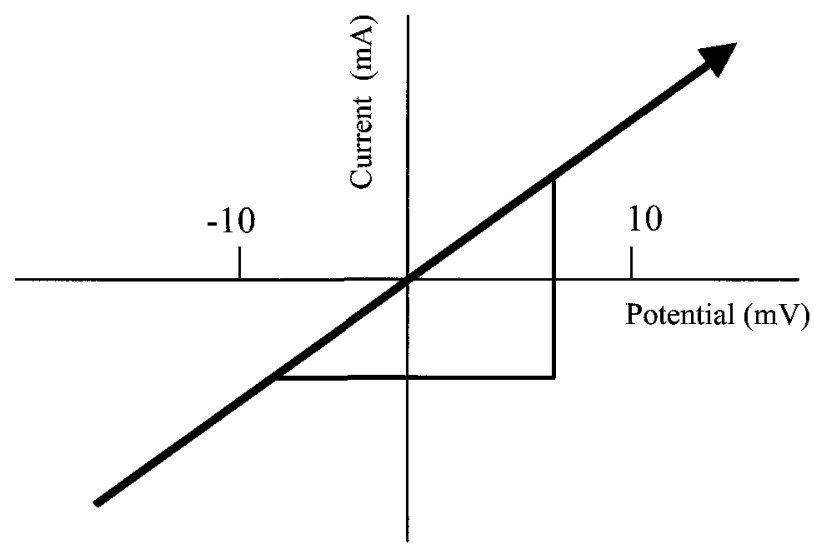

Fig. 1 - Linear plot of the polarization curve around $E_{\text {corr }}$ in the anodic direction.

and the electrochemical measurements has been largely demonstrated $[1,5,10]$.

The measurement is made by a three-electrode arrangement using the reinforcing steel as Working Electrode (WE) as Fig. 1 shows. A Counter Electrode, CE, at least of equal size of the rebar and of a material well dispersing the polarizing current, and a Reference Electrode, RE, serve to apply an electrical signal inducing a shift of about $20 \mathrm{mV}$ from the corrosion potential, either in the anodic or in the cathodic direction.

The $R$, value in $\Omega . \mathrm{cm}^{2}$ is calculated from the ratio $\Delta \mathrm{E} / \Delta \mathrm{I}$ multiplied by the exposed metallic

\section{R. values can be also obtained} transitory period (transient or coul These methods, which will be call for very high speed. meastrement of the ohmic drop, carea (ex
ulostatic in
lescribed
otentiostats expression (2)).
the analysis of the
methods) [24-29].
in paragaph 5.3 ,
ats with precise
d they require the
lectrical model. In specimens with uniform distribution of the applied current,

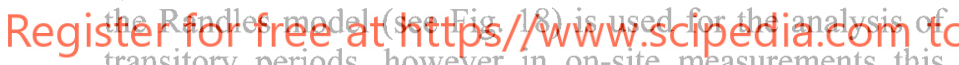
transitory periods, however in on-site measurements this analogue model does not properly represent the phenomenon and therefore, the analysis based on the Randles model of transitory periods recorded in large structures, yields unreliable results.

The Polarization Resistance may also be obtained from Electrochemical Impedance techniques, [30-39]. It is not the aim of the present Recommendation to describe the procedure because its application to on-site measurements proves to be very complex. This is due to the fact that the polarized steel area changes with the frequency and in consequence, the calculation of $R_{p}$, true is not feasible. The model for its interpretation needs further development.

In addition, for the correct measurement of $\mathrm{R}_{\mathrm{p}}$ of metals embedded in concrete the following aspects need to be considered:

1) compensation of IR drop,

2) verification of the range of linearity around $\mathrm{E}_{\text {corr }}$,

3) optimization of the response time by means of a sufficiently long waiting period or proper sweep rate,

4) localized character of the corrosion attack,

5) distinction between galvanic current and corrosion rate

6) comparison with the corresponding gravimetric losses and

7) range of $E_{\text {corr }}$ values in which $R_{p}$ determination of passive steel is reliable.

\subsubsection{Compensation of IR drop}

The relatively high electrical resistivities of the concrete result into too low $\mathrm{I}_{\text {corr }}$ values, if compensation of IR drop is neglected or not adequately performed $[1,5,10]$. This is due to the fact that the $R_{p}$ calculated is the sum of the resistance associated with the actual corrosion process and the resistance associated with the electrolyte resistance (concrete).

\section{$R_{p}$ (calculated $)=R_{p}$ (corrosion) $+R_{e}$ (electrical resistance)}

The potentiostats to be used for on-site measurements have to be able to calculate the ohmic drop, $R_{e}$, or to compensate for its influence during the recording of the $R_{p}$ measurement. Currently, this compensation can be automatically made by means of two methods: positive feed-back, electronically made by the potentiostat, and current interruption, usually as well performed electronically. Both may be equally accurate if made correctly.

\subsubsection{Range of linearity}

The range of linearity of the current-voltage curve (Fig. 1) of steel rebars embedded in concrete has been verified $[1,5]$ for potential ranges around $20-30 \mathrm{mV}[1,15]$ of $\mathrm{E}_{\text {corr. }}$. This relationship is linear for ranges of even $100 \mathrm{mV}$ in the case of very high corrosion rates.

However, the range of linearity may be smaller than $20 \mathrm{mV}$ in some conditions of extremely low corrosion rates

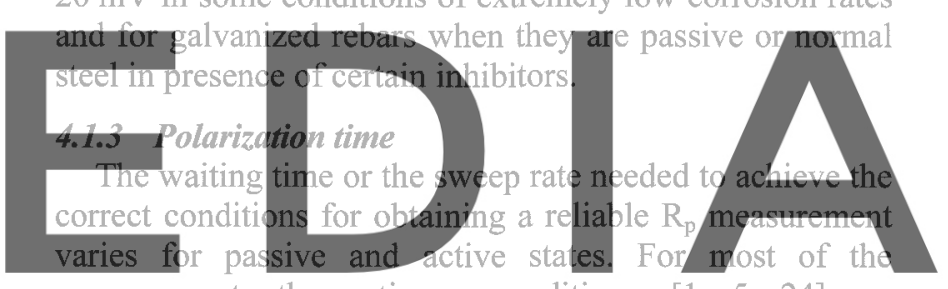
measurements the optimum conditions, $[1,5,24]$ are

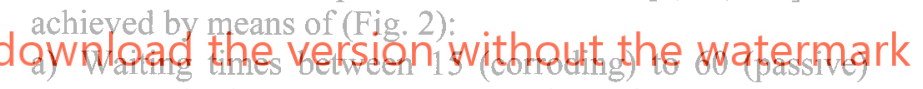
seconds in potentiostatic modes of operation and between 30 to $100 \mathrm{~s}$ in galvanostatic ones.

b) Sweep rates between $2.5-10 \mathrm{mV} / \mathrm{min}$ in potentiodynamic modes of operation.

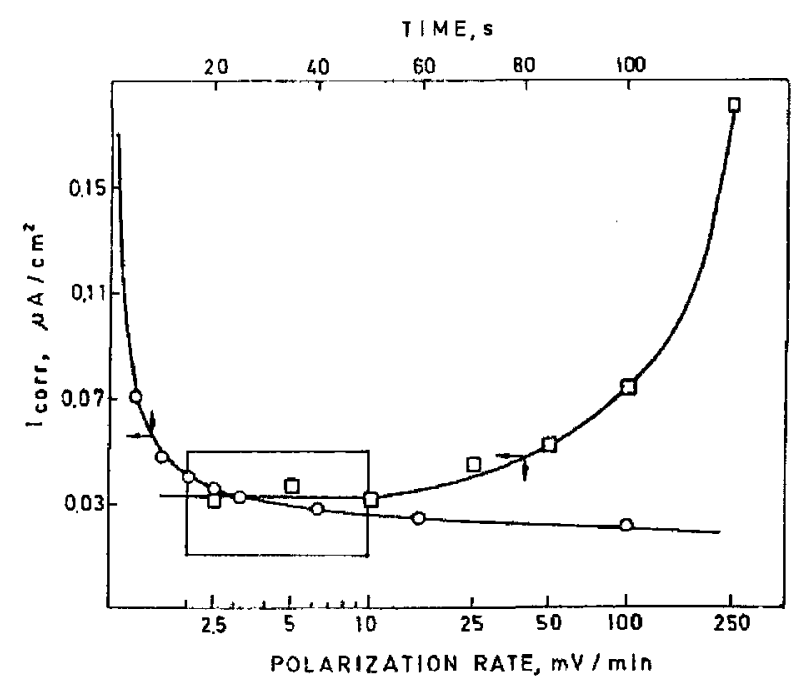

Fig. 2 - Values of $I_{\text {corr }}$ obtained at different polarization times (upper scale) or sweep rates (bottom scale). The range indicated in the window refers to the optimum conditions. 


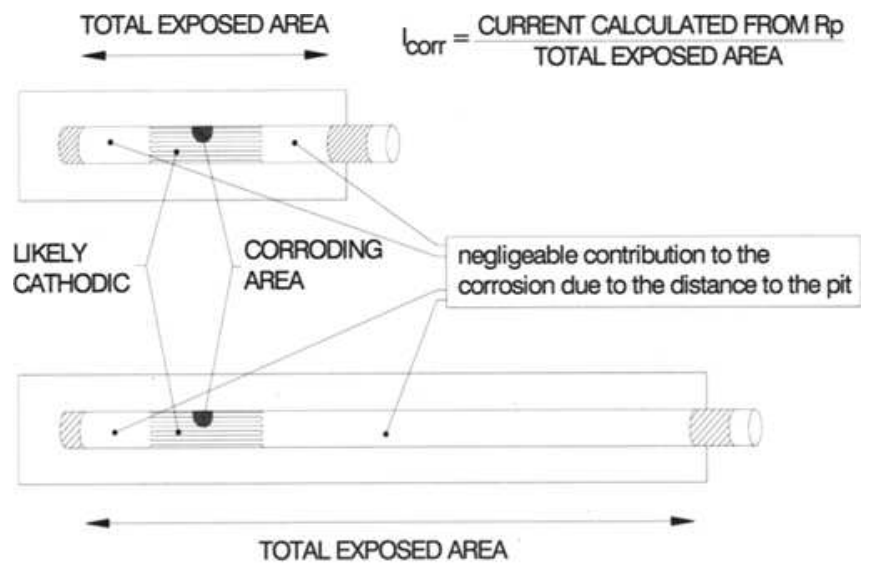

Fig. 3 - Localized attack: Relative error in $\mathrm{I}_{\text {corr }}$ due to sample area. In the case of localized attack the relative error in determination of $I_{\text {corr }}$ is smaller, as smaller is the sample size.

\subsubsection{Localized corrosion}

When the value of the steel area introduced in expression (2) is that of the total area polarized by the applied current, the corrosion current calculated implicitly assumes a uniform distribution and consequently it represents an average corrosion current density, $\mathrm{i}_{\text {corr }}[1,5]$,

When the corrosion is localized in only a small zone of the metallic surface tested, the corrosion gurrent calculated throygh (2) does not represent corrosion current refers to the corroding zone plus the non-cont (cathode) or not (rest of areal cecorded, as Fig. 3 (upper part) rosion current is frequently
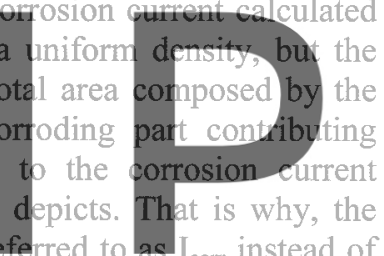
$i_{\text {corr, }}$, indicating a probability that the corrosion morphology

Registeptporforpe at https//www.scipedia.com to

reliability of the $\mathrm{R}_{\mathrm{p}}$ value in the case of localized corrosion.

The first recommendation in order to minimize this error is the use of small size specimens $[1,5]$ which in on-site measurements means the need to polarize small regions of the infinite rebar (to confine the current). Another possibility is to refer the measurement, not to the total steel area, but to the area visually identified to suffer from corrosion (apparent anodic zone) [40, 61]. However, this procedure implies the breaking of the concrete cover for visual observation or the measurement of this area only at the end, area which obviously will be larger than at intermediate steps.

In order to avoid the tedious measurement of the exact surface area actually affected by corrosion, statistical studies have been made for several metals in order to identify the ratio between general and localized corrosion. That is, the ratio between the averaged penetration depth and the maximum pit depth, $\mathrm{P}_{\mathrm{x}} / \mathrm{P}_{\mathrm{pit}}$ (Fig. 4). In the case of reinforced concrete structures [41] a ratio of 10 between $P_{x}$ and $\mathrm{P}_{\text {pit }}$ is recommended to be used as a conservative limit, i.e. this is considered a maximum value. This implies the multiplication of $I_{c o r r}$ values derived from $R_{p}$ measurements by a pitting factor, $\alpha$, having a value of 10 , when localized attack is produced (chloride-induced corrosion). Thus the

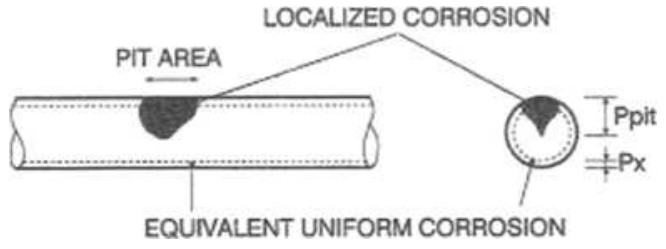

Fig. 4 - Distinction between "corrosion rate" and "local attack penetration". Difference between maximum pit depth $\left(\mathrm{P}_{\mathrm{pit}}\right)$ or maximum attack penetration and the averaged corrosion $\left(\mathbf{P}_{\mathrm{x}}\right)$ : $\mathrm{P}_{\mathrm{pit}}=\alpha \cdot \mathrm{P}_{\mathrm{x}}$

corrosion rate at the pitting site will be the result of multiplying the averaged $\mathrm{I}_{\text {corr }}$ by $\alpha$ (see Equation (12)) [41]:

$$
\mathrm{I}_{\mathrm{pit}}=\mathrm{I}_{\mathrm{corr}} \cdot \alpha
$$

In consequence, using Equation (13) the maximum pit denth will be :

$$
\mathrm{P}_{\mathrm{pit}}=\mathrm{P}_{\mathrm{X}} \cdot \alpha
$$

\subsubsection{Distinction between galvanic current and corrosion} rate

In a corroding zone, both anodic and cathodic areas develop simultaneously. That is, the areas rusting in a corroding reinforcement are not pure anodes, but they have

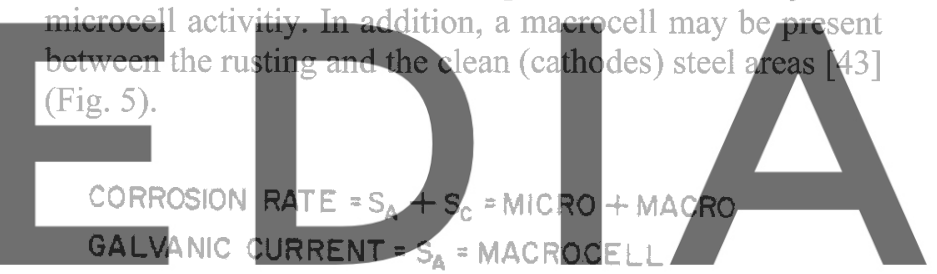

\section{downloaranthe version withdwgthe watermark} "Macrò $\stackrel{P A C R D \rightarrow}{\longrightarrow}$

Fig. 5 - Anodic sites $S_{A}$ present microcell activity in addition to the macrocell formed with the adjacent non-corroding zones, $S_{C}$. $S_{A}+S_{C}=S$ (total area). Galvanic current may be only a fraction of the total corrosion current.

Therefore the galvanic current, $I_{\text {galv }}$, flowing between corroding and passive zones represents only a part of the total corrosion activity. The galvanic current, only equates $\mathrm{I}_{\text {corr }}$ when the corroding part constitutes a pure anode with no microcell activity. This situation might only occur in concrete when a completely oxygen-free atmosphere exists around the corroding areas, or when the corroding area is comparatively very small (small pits) $[7,8]$.

The fact that microcell activity always may exist, even in small pits, prevents a direct correlation to be made between the corrosion rate and galvanic current. That is $\mathrm{I}_{\text {corr }} \geq \mathrm{I}_{\text {galv }}$. The ratio between them will depend on variables such as moisture content (concrete resistivity), size of corroding area and the corrosion rate itself [44].

It is worth noting that the corrosion rate is expressed referred to the whole $\left(S_{A}+S_{C}\right)$ surface area (Fig. 5), while galvanic current $I_{\text {galv }}$ is usually referred only to the corroding $\left(S_{A}=\right.$ anodic $)$ zone $[43,44]$. 


\subsubsection{Comparison with gravimetrically determined weight losses}

The metallic mass loss after suffering corrosion is measured by the difference in weight of the metal cleaned of any oxide before been submitted to the corrosion process and after being removed from the concrete. This gravimetric loss has to be the same than that calculated through Faraday's law from the integration of the $\mathrm{I}_{\text {corr }}$-time curve $[1,5,10]$. The instantaneous values of the $\mathrm{I}_{\text {corr }}$ are represented along the time as shown in Fig. 6. for mortars with several amounts of chlorides added in the mix. The integration of this type of plot is what is compared with the gravimetric losses.

The graph showing the comparison between gravimetrically determined and electrochemically derived metal losses is depicted by Fig. 7. The results must lie around the line of equality with a maximum error factor of two (3). This error factor is depicted by the two lines lying parallel to the line of equivalence in the figure. This type of checking is essential to validate any measurement of $\mathrm{I}_{\mathrm{corr}}$

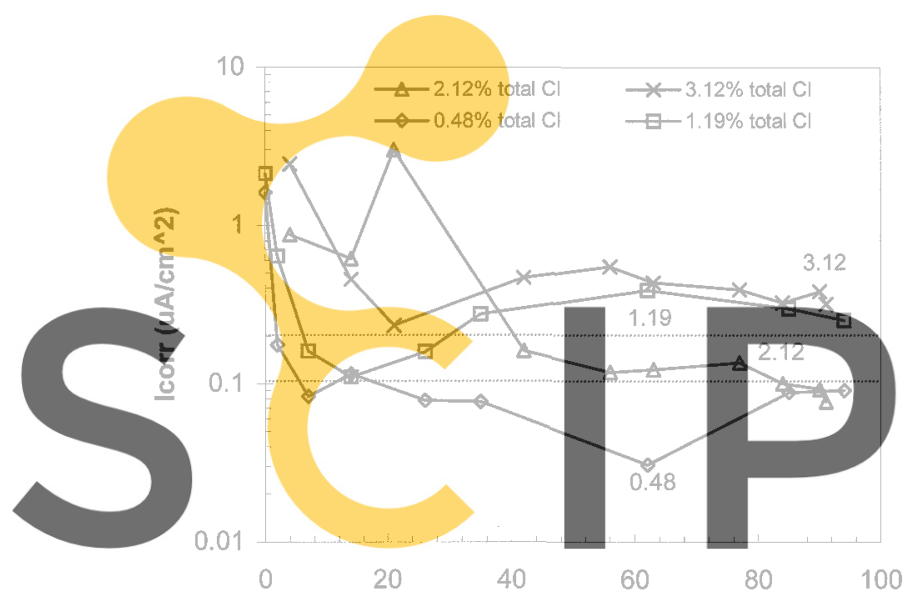

Register for free at httpsinge

Fig. 6 - Examples of $\mathrm{I}_{\text {corr }}$ time plots of rebars embedded in mortar with different proportions of chlorides added in the mix.

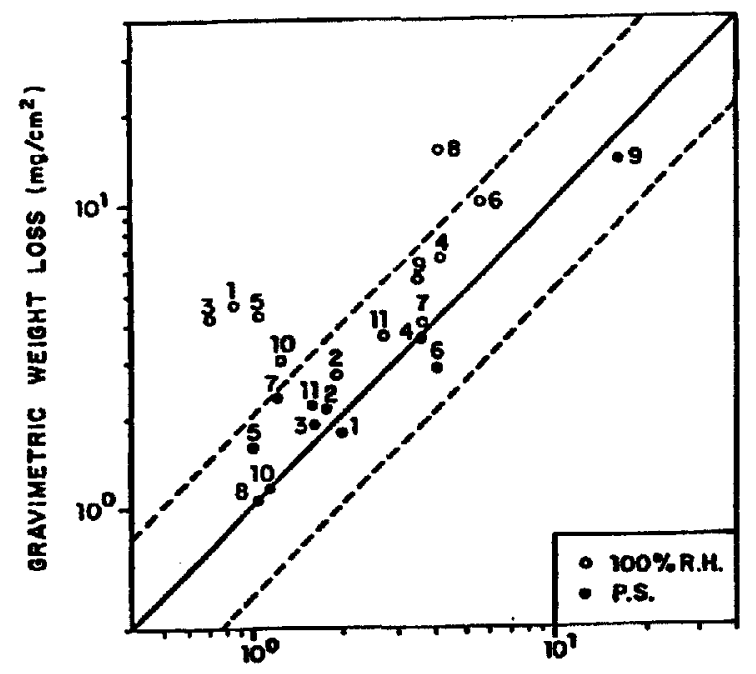

Fig. 7 - Comparison between gravimetrically determined losses and electrochemical ones (obtained from the integration of the $\mathrm{I}_{\text {corr }}$ - time plots). The dotted parallel lines delimitate the range of accuracy obtainable (a factor of two times the actual value). values, although in large structures the determination of the gravimetric loss is only feasible if the reinforcement bar is carefully cut in small portions.

\subsubsection{Range of $E_{\text {corr }}$ for reliable $R_{p}$ determination in passivated steel}

It has been recently realized [45-48] that $R_{p}$ values cannot be correctly determinated if the steel is passive and exhibits $\mathrm{E}_{\text {corr }}$ values more cathodic than around $-300 \mathrm{mV}$ (SCE) due to a restricted access of oxygen, as it may happen in submerged structures. In these cases, the $R_{p}$ values measured may be too low (too high corrosion) and in consequence, to mislead the correct determination of $\mathrm{I}_{\text {corr }}$. The most likely explanation is that at these cathodic potentials in passive state, the measurement of $R_{p}$ seems to give the current exchange of the redox process (Fe (II) $\leftrightarrow$ Fe(III)) in the passive layer. This fact has not been so clearly noticed in actively corroding steel because it is likely to be masked by the relatively higher importance of the faradaic process in comparison to the redox one.

As a practical consequence, the values of $R_{p}$ recorded on passive reinforcements or where a lack of oxygen is suspected (as may be in concrete being very saturated by water or chlorides), have to be carefully interpreted by specialists.

\subsection{Particularities of on-site measurements:} determination of the polarised area or current

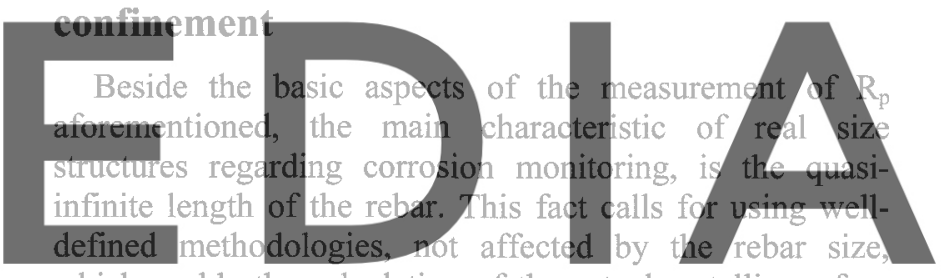

which enable the calculation of the actual metallic surface being effectively polarized during the measurement.

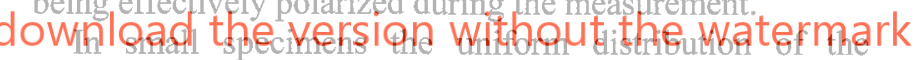

current applied between auxiliary and working electrodes is usually guaranteed. However in large structures, the auxiliary electrode is much smaller in size than the working electrode (the rebar). This situation gives rise to an essentially non-uniform distribution of the applied current along the reinforcement as shown in Fig. 8 [4]. The electrical signal tends to vanish with the distance from the

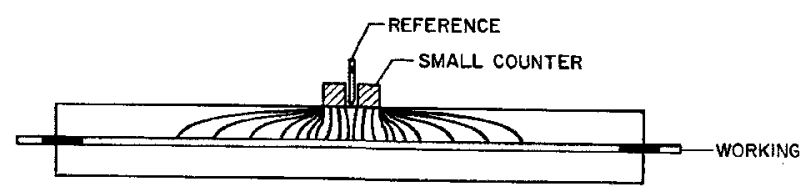

Fig. 8 - Lateral spreading of the current when applied through a small counter electrode.

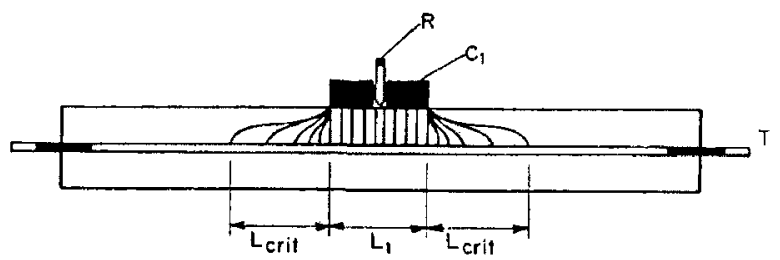

Fig. 9 - The length of the rebar polarized to a significant level by the externally applied current is termed the "critical length", $\mathrm{L}_{\text {crit }} \cdot \mathrm{RE}=$ Reference electrode, $\mathrm{CE}=$ counter electrode. 
counter electrode, $\mathrm{CE}$. The required uniform distribution is, therefore, not met and the $\Delta \mathrm{E} / \Delta \mathrm{I}$ slope cannot be referred to any specific rebar surface.

In consequence, either the so-called critical length, $\mathrm{L}_{\text {crit, }}$ (see Fig. 9) reached by the electrical field has to be calculated or the current has to be confined within a welldefined delimited area.

\subsubsection{Critical length}

The critical length, $\mathrm{L}_{\text {crit }},[4,49]$ is named the distance reached by approximately $90 \%$ of the current applied by means of a small auxiliary electrode placed on the surface of the concrete as Fig. 9 depicts. It is the distance reached by the current relative to the border of the external auxiliary electrode.

This critical length is a function of the square root of the ratio $R_{p} / R_{e}$ [25] and independent of the size of the counter electrode. It is not a fixed length, $L$, value. It can be calculated by means of the transmission line model [4] (Fig. 10).
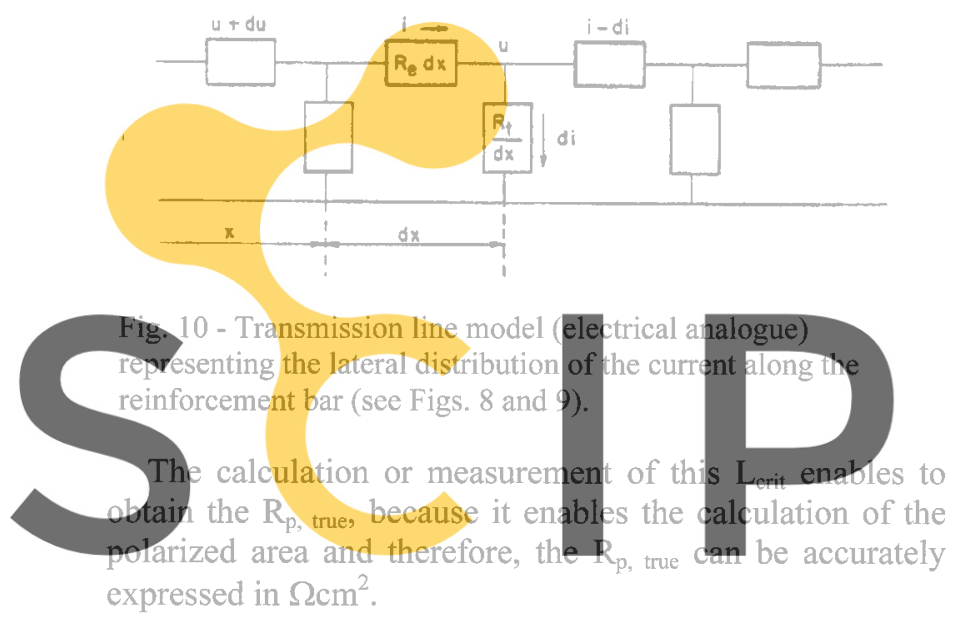

\section{Registere farpdreet at dettipstowww.scipedia.com to}

If the ratio $\Delta \mathrm{E} / \Delta \mathrm{I}$ is obtained without referring to $\mathrm{L}_{\text {crit }}$ but, for instance, is calculated only from the CE area, an $\mathrm{R}_{\mathrm{p} \text {,app }}$ is obtained, [4, 49] which results in serious errors if used for quantitative calculations, because large differences between $\mathrm{R}_{\mathrm{p} \text {, true }}$ and this $\mathrm{R}_{\mathrm{p} \text {, app }}$ may exist.

Thus, in Fig. 11 the error factor $\left(R_{p} / R_{p}\right.$, app $)$ is shown. The

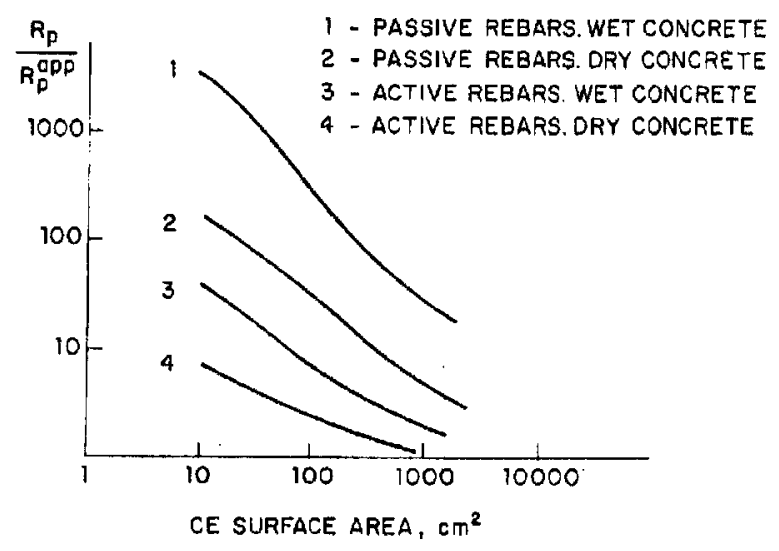

Fig. 11 - Error factor $\mathrm{R}_{\mathrm{p} \text {, true }} / \mathrm{R}_{\mathrm{p} \text {, app }}$ as a function of the area of the counter electrode when this area is used for calculating $R_{p, a p p}$. values have been confirmed in experiments made in large slabs. In the case of non-corroding rebars the error factor easily exceeds a value of 100 , whereas for corroding rebars, it may be about 10 or smaller. The ratio $R_{p} / R_{p, a p p}$ will depend on the value of the particular $R_{p}$ itself and of the concrete resistivity (level of concrete moisture content).

A general or fixed value of this error factor cannot be given due to the variability of moisture conditions and degree of chloride contamination of the concrete which affect both $R_{e}$ and $R_{p}$. That is, it does not produce a single value for the error factor relating $R_{p \text {, true }}$ and $R_{p \text {, app }}$ values.

\subsubsection{Confinement of the polarizing current}

Another way of delimitation of the area actually polarized by the applied current consists in using an external circular counter electrode concentric to the $\mathrm{CE}$ termed"guard ring", GR [49-51]. This arrangement enables the current applied through the central $\mathrm{CE}$ to be confined to a defined area under the central CE and between it and the external GR, providing the polarization achieved by this GR is adjusted precisely to counterbalance the central electrical field (Fig. 12). If the counter-field from the GR is not correctly controlled and adjusted, the area being polarized may greatly differ (being smaller or larger) from the predetermined one. This control is achieved by means of two additional reference electrodes, $\mathrm{S}_{1}$ and $\mathrm{S}_{2}$, located between $\mathrm{CE}$ and GR as will be commented in paragraph 5.1. Fig. 13 shows an example of a lack of correct
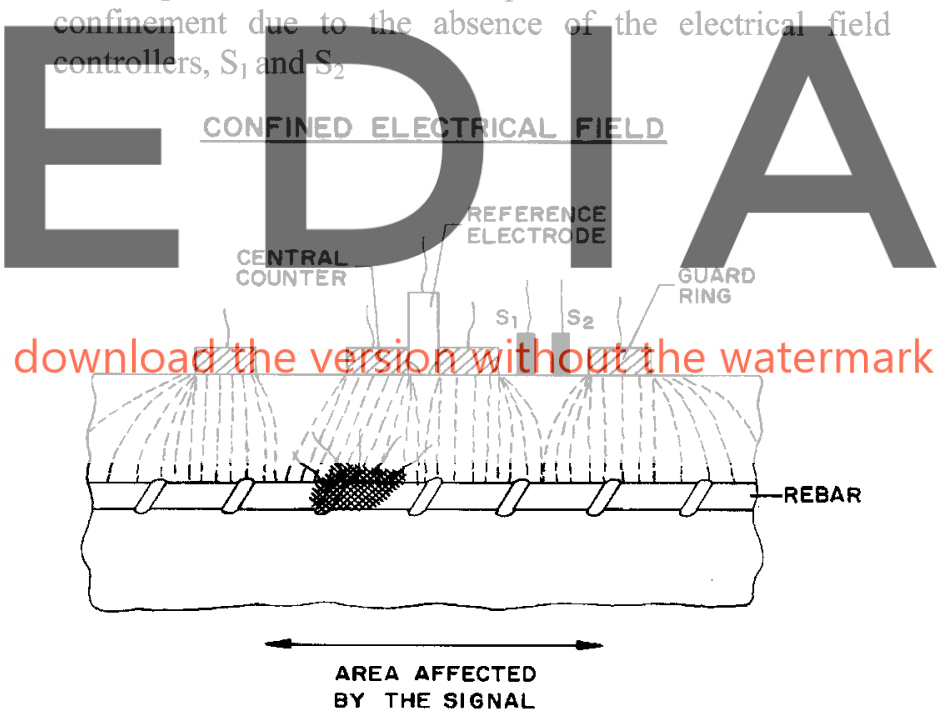

Fig. 12 - Theoretical confinement of the applied current introduced by the central counter electrode, when an external guard ring is used to produce another counterbalancing electrical field.

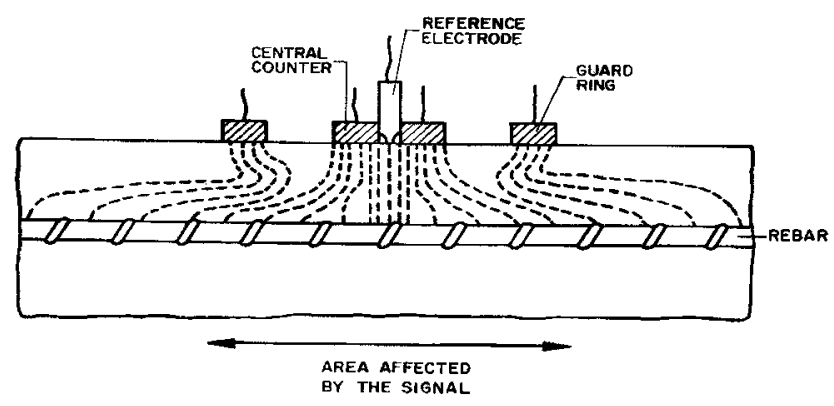

Fig. 13 - Incorrect confinement of the current when the guard ring does not have an independent control or modulation. 


\subsubsection{Detection of localized corrosion}

When the corrosion is very localized, an error in the calculation is produced which is proportional to the relative size ratio of the corroding area to the total area (see paragraph 4.1.4). The larger the total polarized area, the higher will be the relative error $[40,51]$.

In the case of on-site measurements, the locally corroding spots change the current lines from the central CE resulting into a non uniform distribution as Fig. 14 depicts. This effect invalidates not only the calculation of $I_{\text {corr }}$ but also the assessment of the location of the pits. The non-confining techniques are not able to correctly localize the isolated corroding zones, because they draw the applied current tens of $\mathrm{cm}$ away from the $\mathrm{CE}$. On the opposite, the technique using a modulated guard ring enables the correct identification of the localized corrosion spots as was shown in Fig. 12.

\section{NOT CONFINED ELECTRICAL FIELD}

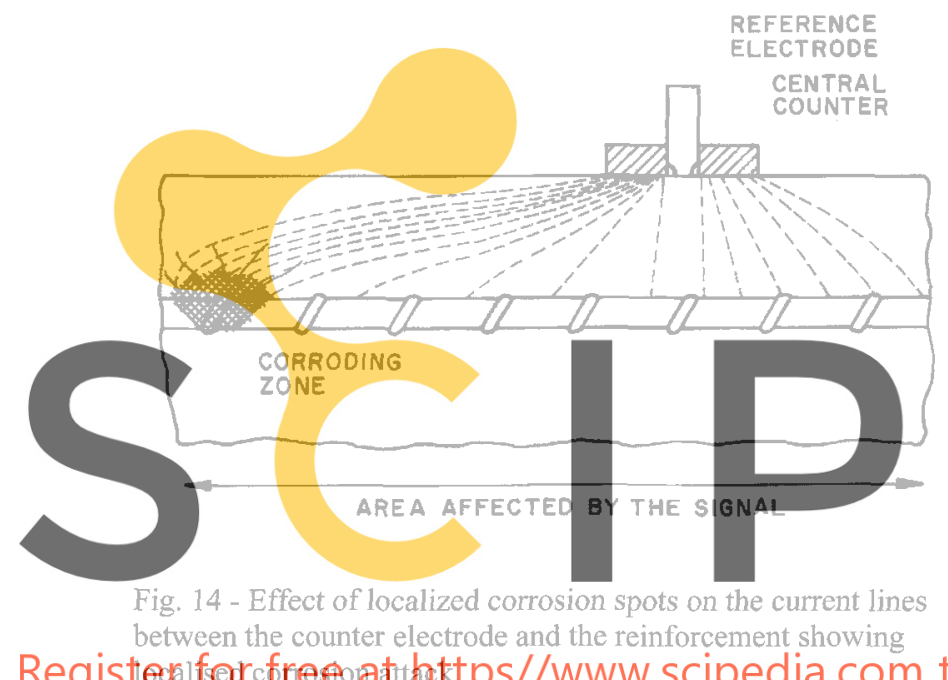

\section{METHODS FOR ON-SITE MEASUREMENT OF THE POLARIZATION RESISTANCE}

In order to solve the uncertainty of the rebar surface really polarized by the applied current, the methods of measurement developed until now are based on the following principles:

a) The confinement of the applied current to a predetermined area by means of a "modulated" guard ring (second circular counter electrode applying a modulated counter current).

b) The calculation of the critical length reached by the current when applied from a small auxiliary electrode placed on the surface of the concrete. This calculation might be made through the following methods: (1) Multiple electrode or potential attenuation method and (2) Galvanostatic pulse or transient analysis. This last one presents the inconvenience of the need to use several electrical analogue models for being accurate. c) The use of a pair of large size auxiliary electrodes, which minimize the effect of the critical length. This method has the inconvenience that, as the counter electrodes have to be large, the method is not sufficiently sensitive to localized attack. Therefore, this method will not be described in the present Recommendation.

\subsection{Modulated confinement of the applied current (guard ring) method}

This method $[4,49]$ is based on the calculation of the $R_{p, t r u e}$ using effective confinement of the polarizing current within a specific area through a second circular counter electrode This so-called "guard ring" is modulated by means of two twin reference electrodes, $S_{1}$ and $S_{2}$, located between the central CE and the external GR (Fig. 15) in order to achieve the required counterbalancing electrical field. These twin electrodes permanently control the external ring by means of detecting the current lines coming from the CE in order to adjust them within the predetermined area of diameter $\mathrm{D}$. The method then promotes an electrical delimitation of the area instead of determining it.

Therefore, the auxiliary electrode for confined measurement consists of (Fig. 15):

a) a central small counter $\mathrm{CE}$,

b) a ring-shaped counter electrode, GR, which surrounds the central one,

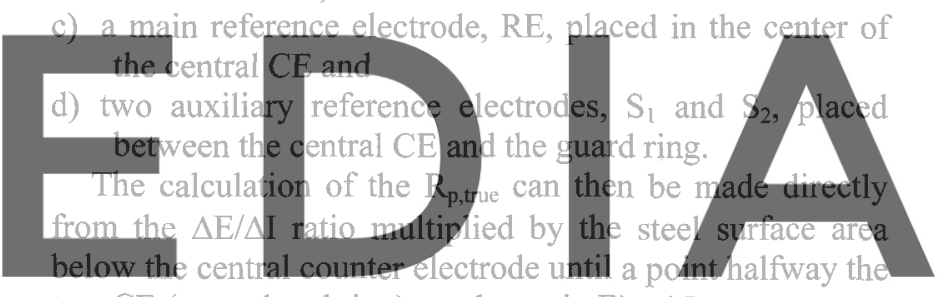

two CE (central and ring), as shown in Fig. 15.

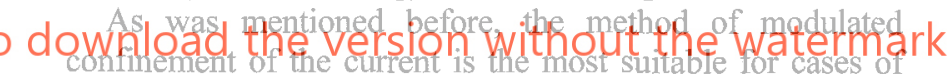

localized attack, because it delimitates the area polarized and therefore, it is able to reduce the inherent error due to the relative area sizes (Fig. 3). Moreover it is the only method

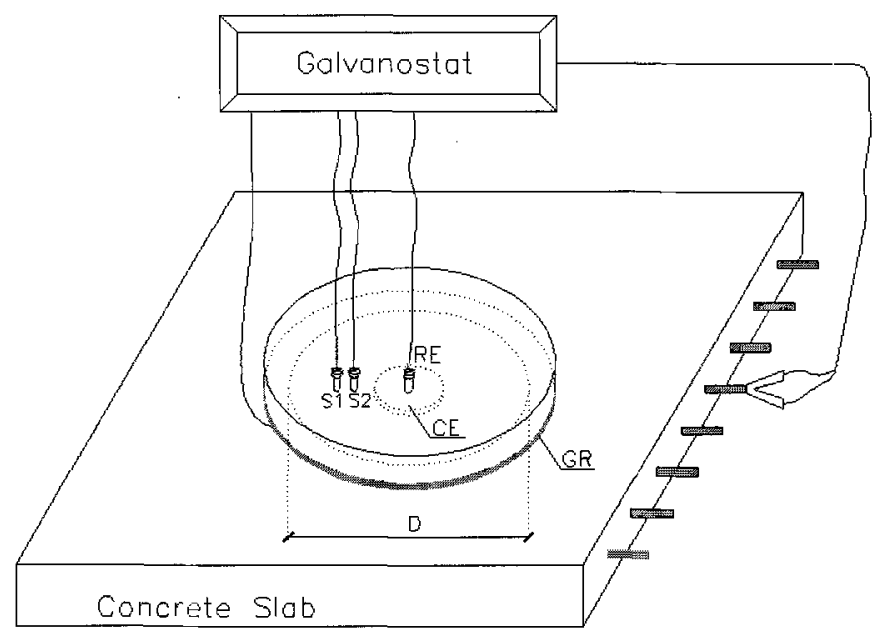

Fig. 15 - Arrangement of electrodes in the modulated confinement of the applied current. The reference electrodes $S_{1}$ and $S_{2}$ are used to modulate the outer guard ring in order to effectively confine the current to the circular area indicated by the dotted line. 
which is able to minimize the effect of macrocells or to notice active/passive region transition.

\subsection{Multiple electrode or potential attenuation method}

This method [54] is based on the calculation of the critical length, $L_{\text {crit }}$, which allows calculation of the steel area really polarized by the applied current by means of the transmission line model.

The method makes use of a small counter electrode, CE which is placed on the concrete surface, as depicted in Fig. 16. In the center of this $\mathrm{CE}$ electrode the main Reference electrode, $\mathrm{RE}$, is placed which measures the local corrosion potential $\mathrm{E}_{\mathrm{corr}}$ of the reinforcing steel. Other
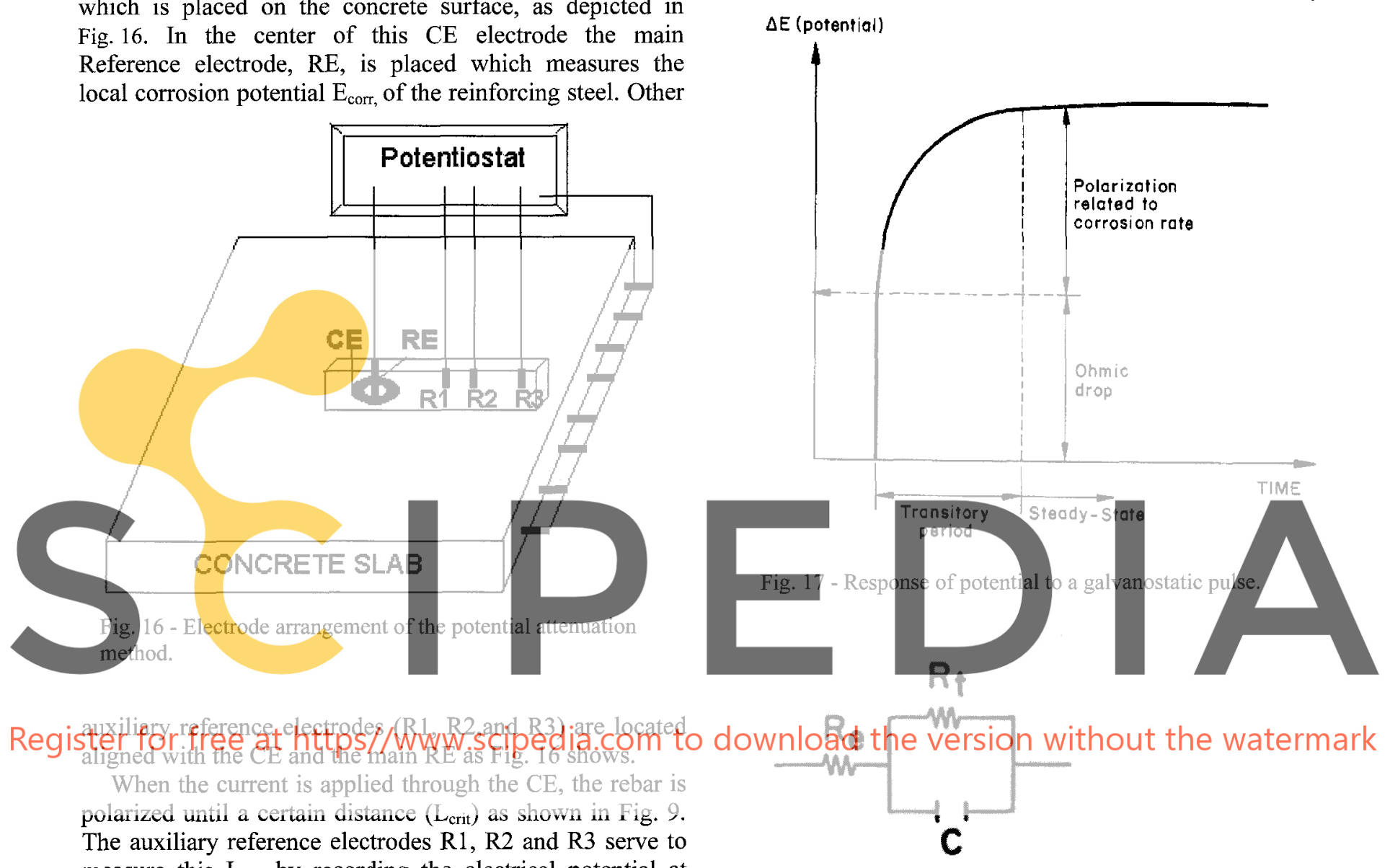
The auxiliary reference electrodes R1, R2 and R3 serve to measure this $\mathrm{L}_{\text {crit }}$ by recording the electrical potential at various distances from $\mathrm{CE}$ (potential attenuation) before and after the application of the current. The position where this potential difference is smaller than approximately $10 \%$ of the potential difference calculated from RE indicates $\mathrm{L}_{\text {crit }}$ and therefore, allows to calculate the geometrical rebar area really polarized by the signal.

As soon as the polarized area is known and the geometrical characteristics of the concrete element are determined, the corrosion current, $\mathrm{I}_{\text {corr }}$, can be calculated.

This method is the only one able to correctly determine a $I_{\text {corr }}$ in submerged structures. The modulated guard ring method cannot be applied due to the low resistivity in these conditions.

\subsection{Galvanostatic pulse or transient analysis methods}

Several procedures $[25,27,50-53]$ have made use of the recording of the transient response after the application of a galvanostatic pulse. The method uses the typical arrangement of unconfining techniques of a single counter electrode having a Reference Electrode at its centre. The use of a nonmodulated guard ring has been tried as well [28]. A current pulse of several tens of $\mu \mathrm{A}$ to several $\mathrm{mA}$ is applied by means of the counter electrode, and the potential-time response is recorded (Fig. 17).

For the calculation of the $R_{p}$ an "analogue or electrical model" is used which simulates the steel/electrolyte interface (double layer) through a capacitance and the faradaic corrosion (weight loss) through a resistance. The model used is the well known Randles circuit shown in Fig. 18. where the capacitor,

Fig. 18 - Randles circuit or electrical analogue model of metal/electrolyte interference. The circuit is too simple for modelling the dispersion of the applied current in real size structures.

$C$, represents the double layer and the resistor, $R_{t}$, the polarization resistance, that is the resistance to corrosion or to the loss of metal integrity.

The $R_{p}$-value can be calculated by solving the circuit of Fig. 18 resulting [24] into:

$$
\frac{\Delta E}{\Delta I}=R_{p}\left(1-e^{-t / R p C}\right)+R_{\theta}
$$

This technique seems very attractive as it is very quick (it tries to measure during the transitory period), however it has several problems, which are mentioned below:

a) to accurately record the response in so short times is very difficult as very quick response potentiostats are needed, which have the inconvenience of not being able to measure the very low currents recorded in passive state, 
b) to accurately measure the ohmic drop, because it may represent an important proportion of the potential during the transitory period,

c) the need to assume a value of the capacitance for calculating $R_{p}$, which in the case of concrete is not a fixed value and even pseudo-capacitances may develop, and

d) that unconfined or inadequately modulated techniques are unable to precisely locate the corroding spots and pits (Fig. 14).

Due to these difficulties, up to now pulse techniques have not succeeded in measuring accurately in large structures. The use of a guard ring has not improved the results as it presents the additional inconveniences described in paragraphs 4.2 .3 and 4.2 .4 (Figs 13 and 14) related to the difficulty of modulating the guard ring during the transitory period.

\subsection{Large size auxiliary electrode}

Other procedures to measure on site are based on the use of unguarded techniques with a single relatively large central counter electrode and its surface is used as a reference area for the corrosion measured (multiplying the $R_{p}$ by the area of the counter) [54].

As the critical length $\mathrm{L}_{\text {crit, }}$ is not dependent on the size of the counter electrode, one method of measurement might be the use of large size electrodes in order to make the polarized area below them, comparatively bigger than that corresponding to the critical length. Thus, for passive conditions, auxiliary electrodes of minimize the error of not accoun encountered in the critical length, enough in the case of active corrosion multiplied by the area of the counter elect

However, the use of large auxiliary counter electrodes has the important inconyenjence of not being able to detect be a practical way of measuring in very wet conditions, where a uniform corrosion morphology might be expected and other methods may fail or give erroneous results.

\section{PRACTICAL EXECUTION OF MEASUREMENTS}

\subsection{Apparatus}

\subsubsection{Electronic equipment}

The equipment to be used with any of the methods described in chapter 5 has to be based on a potentiostat or galvanostat as a means of controlling and measuring potential and current.

The potential measuring circuit of the instrument should be able to maintain an electrode potential within $1 \mathrm{mV}$ over a wide range of currents and should have a high input impedance, i.e. higher than $10 \mathrm{M} \Omega$, in order to minimize current drawn from the corroding system during measurements.

The current circuit should have a sensitivity such that the $I_{\text {corr }}$ could be determined at least of the order of $0.05 \mu \mathrm{A} / \mathrm{cm}^{2}$. Furthermore the instrument should have a sensitivity to detect variations of $0.5 \mathrm{mV}$ in a potential range from $-1.0 \mathrm{~V}$ to $+1.0 \mathrm{~V}$. The current circuit must have a sensitivity of at least $0.05 \mu \mathrm{A}$ in the full range between 0.05 to $10^{4} \mu \mathrm{A}$.

The potential or the current is applied, resulting into:

a) a sweep potentiodynamic polarization around $\mathrm{E}_{\text {corr. }}$.

b) a stepwise polarization using single small potential or current steps.

Potentiodynamic or galvanostatic measurements allow for the calculation of the slope $\Delta \mathrm{E} / \Delta \mathrm{I}$, which has to be multiplied by the rebar surface effectively polarized by the electrical signal in order to obtain the True $R_{p}$ in ohm $\mathrm{cm}^{2}$. The procedure was explained in chapter 5 for the different measurement methods.

Concerning the optimum polarization time, corroding rebars need shorter polarization periods while passive steel needs longer waiting times to reach a stable value. In potentiostatic measurements, waiting times of 15-60 seconds are enough to achieve the quasi-stationary regime necessary to obtain the $\Delta \mathrm{I}$ value to be used in the expression $\Delta \mathrm{E} / \Delta \mathrm{I}=\mathrm{R}_{\mathrm{p}}$. This ratio also has to be multiplied by the metallic area really/effectively polarized. In galvanostatic measurements, longer waiting times may be necessary to record a quasi-stationary $\Delta \mathrm{E}$ value: periods of $30-100$ seconds are the most appropriate. As has been said (paragraph 4.1.3), the shorter waiting times are recommended for an active corrosion state, while the longer

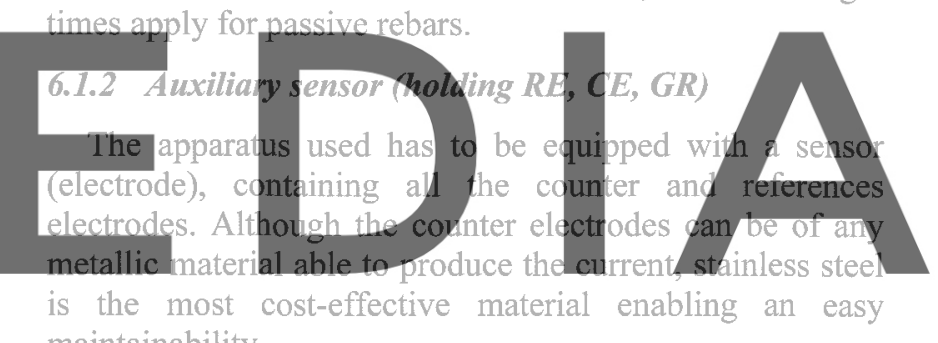
dowaintainabilititie version without the watermark traditional ones: calomel, silver/silver chloride or copper/copper sulphate. This last one has demonstrated to be one of the most suitable due to its measurement range, accuracy and precision, although it has to be maintained and its junction membrane cleaned periodically.

\subsubsection{Contact sponge between auxiliary sensor and concrete surface}

In order to provide a low electrical resistance path between the sensor and the concrete surface, a wet sponge or any other conductive substance or cloth has to be used. The sponge and the concrete surface have to be prewetted with water or any other low electrical resistance contact solution or gel. The concrete prewetting should be intensive enough to establish a good electrolytic contact (see paragraph 6.2.1.)

\subsection{Calibration and Standardization}

\subsubsection{Equipment}

The calibration of the portable potentiostat/galvanostat can be made in a similar way to non-portable ones. The equipment can be checked by means of carrying out measurements with a dummy cell. This electrical analogue cell can be fabricated by using a Randles circuit of the type 
of Fig. 18. Orientative values of the elements of the circuit are: $R_{e}=10 \mathrm{k} \Omega$, for wet concrete and around $50-100 \mathrm{k} \Omega$ for dry concrete, $R_{p}=5 \mathrm{k} \Omega$ for representing an active state and $R_{p}=100 \mathrm{k} \Omega$ for reproducing a passive state of the steel The capacitance representing the steel may be $\mathrm{C}=50 \mu \mathrm{F}$.

Also a transmission line model of the type reproduced in Fig. 10 can be used. The values of the elements can be the same as those for the Randles circuit.

In all cases the potentiostat has to give the values of the circuit within the range of error given by the electrical elements used to build the dummy cell.

\subsubsection{Reference electrodes}

The reference electrodes of the auxiliary sensor used as counter electrode have to be checked periodically in order to detect any improper functioning due to drying of the porous plug or leakage of the solution. This checking is performed by comparing their corrosion potential values with those obtained at the same location with other independent electrodes of the same nature.

\subsection{Standard reference measurements}

The whole apparatus has to be, at least initially, standardized by comparing its results with those obtained by means of a normal potentiostat in reference concrete slabs (under laboratory conditions)

\section{Procedure}

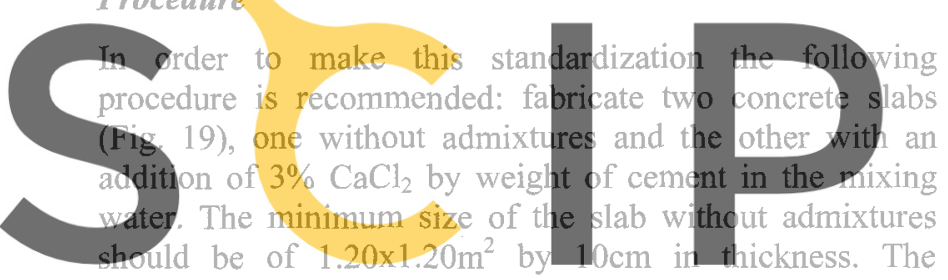
minimum size of the chloride contaminated one should be

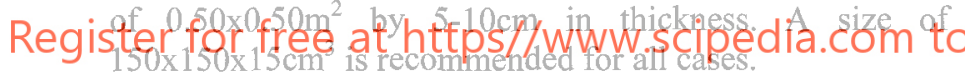

Then, 5 to 10 isolated rebars have to be embedded as is shown in Fig. 19. Means to make an external electrical connection between rebars have to be provided. Simple

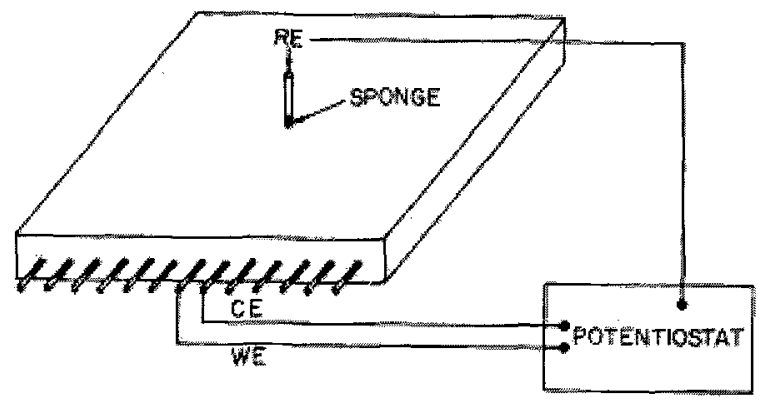

Fig. 19 - Slab type for making reference measurements for calibration of portable corrosion-rate-meters.

wires with plugs are a suitable method for the verification of proper electrical conductivity.

In order to make the reference measurements the bars have to be initially unconnected. Take one of the central bars as working electrode and the adjacent one as counter auxiliary (denoted $\mathrm{CE}$ in Fig. 19). Place a reference electrode (denoted RE in the figure) above the working electrode, making the electrolytic connection by means of a wet sponge. Carry out a $R_{p}$ measurement with a normal potentiostat and calculate the $\Delta \mathrm{E} / \Delta \mathrm{I}$ ratio of this central rebar. Multiply the "ohms" so obtained by the area of the working electrode (area $=\pi \mathrm{DL}$, where $\mathrm{D}=$ rebar diameter and $L=$ embedded length of the rebar) in order to obtain $R_{p}$ in $\mathrm{ohm} \cdot \mathrm{cm}^{2}$.

Repeat the measurements placing the reference electrode at two additional points along the rebar and calculate the arithmetic mean of the three results. Give this value as the reference one: $R_{p \text {, ref }}$.

Now, make connection through an external wire between all the rebars in order to reproduce reality. Take the instrument to be calibrated and place the Auxiliary sensor on the concrete surface, providing electrolytic adequate interfacial contact has been achieved. Make the connection to one of the rebars providing the whole mat is connected. Carry out the $R_{p}$ measurement. Give the value in $\mathrm{ohm} \cdot \mathrm{cm}^{2}$ following the instructions of the equipment in order to consider the area really polarized by the current.

In the case of the slabs contaminated with chlorides the value of the $R_{p}$ obtained with the instrument has to be between double and half of $R_{p}$, ref:

$$
0.5 R_{p, \text { ref }}<R_{p}<2 R_{p, \text { ref }}
$$

In the case of the passive rebars the $\mathrm{R}_{\mathrm{p}}$ obtained through the on-site instrument should fulfil the requirement (8) or give $\mathrm{I}_{\mathrm{cor}}$ - values lower than $0.2 \mu \mathrm{A} / \mathrm{cm}^{2}$
6.4 Precision and bias
The repeatability of the $\mathrm{I}_{\text {corr }}$ results, requires more that
10 measurements taken. at the same location and
comparable environmental conditions should be such that
$90 \%$ of the measurements should not differ not more than four times the minimum value recorded. For instance, a

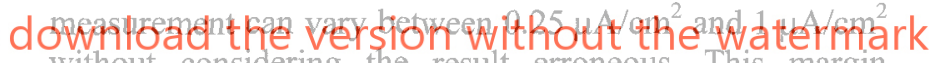
without considering the result erroneous. This margin appears as a consequence of the factor of two inherent to the Polarization Resistance method [3].

However, $I_{\text {corr }}$ values taken on the same rebar but in different points do not have to fulfil this criterion, because localized corrosion may give different $I_{\text {corr }}$ values with only a few centimetres of distance along the rebar.

Deviations from these criteria indicate improper functioning of the instrument.

Time to recover between successive measurements for a stable $\mathrm{E}_{\text {corr }}$ potential should be considered. In general, the recovery of the potential varies from some few seconds to several minutes.

\subsection{Practical procedure}

This section contains information on the practical procedure for carrying out the measurements on site, as well as on the sources of error and the recommended frequency (geometrical and in time) of measurements.

\subsubsection{Sequence of operations}

The sequence of operations necessary for measuring the corrosion rate on-site is:

- Preparatory considerations on concrete conditions due to weather effects 
- Selection and identification of measurement location

- Identification of rebar location

- Coordinate system for measurements

- Preparation of the concrete surface by prewetting

- Placement and fixation of the auxiliary sensor at the measurement location.

- Connection between equipment and reinforcement.

- Execution of the measurement.

From these operations, the most important details are commented in the following paragraphs.

\subsubsection{Preparatory considerations on concrete conditions due to weather effects}

Corrosion rate equipment, as other electronic devices, does not work in extreme conditions of temperature or humidity. The devices should not be at operated at temperatures below $2^{\circ} \mathrm{C}\left(36^{\circ} \mathrm{F}\right)$, or allowed to get over $50^{\circ} \mathrm{C}\left(122^{\circ} \mathrm{F}\right)$. If the environment exceeds these limits, then the meter has to be operated from an air conditioned enclosure or vehicle.

It should be noted that below freezing, the wetted sponge may freeze giving misleading or unstable readings. However, if it is still considered essential to collect data under these conditions then an alcohol solution $(10-30 \%$ of alcohol by weight) will reduce the freezing point. It should also be noted that below $5^{\circ} \mathrm{C}$ the corrosion rate may reduce to low values which may mislead the interpretation ( $\mathrm{Re}$ may be very high/I $\mathrm{I}_{\text {corr }}$ very low).

Complete water saturation of concrete may also lead into measurement difficulties due to the high conductivity path that may be established through the concrete surface. This is particularly clear when deicing salts have been used. The extremely conductive concrete surface may facilitate the dispersion of the current lines to very long distance which makes it difficult to obtain a reliable or reproducible $R_{p}$ value. That is why measurements in submerged structures may give very unreliable results, unless the method described in 5.2 (attenuation of potential) is used.

\subsubsection{Selection of number and measurement locations}

Before starting the survey it is necessary to select the number and location of points where corrosion rates will be measured. The number of points will depend upon: a) the amount of time available, access, and size of structure and, b) the aim of the inspection (see chapters 6.3 and 8).

The operator must first consider the time which is required to get access to each location, to perform other relevant measurements and other logistical factors associated with site work. Obviously experience is important in being able to collect the most useful data for a reasonable expenditure of time and effort. The previous measurements of chloride concentration, rust staining, cover, carbonation depths, corrosion potential and resistivity, etc. can also be used as indications for selecting the most appropriate measurement points. That is, measurements may be taken at strategic locations chosen because they represent one or more of the following:

- High or low readings from half cell potentials or concrete resistivity.

- Locations of structural importance (different elements, construction joints, sources of water or chloride, ground, water level etc.).

With regard to the duration of each corrosion rate measurement, each reading may take from less than 1 minute to about 5 minutes depending upon the actual corrosion conditions and the method of measurement. The physical processing of placing the sensor may also take a time of 2-5 minutes. So the operator must consider 5 to 15 minutes per location to obtain a corrosion rate measurement.

\subsubsection{Identification of rebar location}

The actual geometry of the rebar arrangement is made by using a steel detector. If needed the bar pattern can be marked on the concrete surface, as well as the cover depth registered. The bar diameter and their distances are needed for the calculation of the steel area to be polarized during the measurements

\subsubsection{Coordinate system for measurements}

When it is decided to map a zone or element, measurements should be taken on a grid. It is recommended that readings are taken over a rebar, so the grid size is partly dependent on the rebar spacing. A $0.25 \mathrm{~m}$ grid spacing is recommended, except on small structures or elements with severe changes in exposure conditions. An example of a $\mathrm{I}_{\text {corr }}$

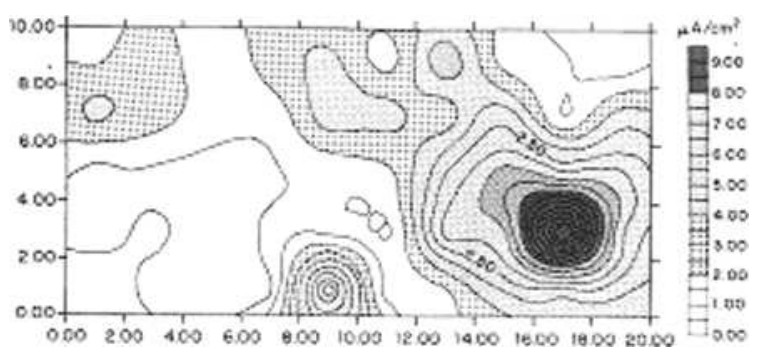

Fig. 20 - Map of corrosion rate values in a slab.

map is shown in Fig. 20.

Measurements may also be taken on a simple straight line, if the corrosion condition is likely to vary with distance along an element.

\subsubsection{Preparation of the concrete surface by prewetting}

The concrete surface has to be well wetted prior to applying the Auxiliary sensor. Care has to be taken to avoid contamination of the reference electrodes with alkaline substances from the concrete. This is achieved by simply placing a clean wetted sponge between the sensor and the concrete surface.

On coated or hydrophobically treated surfaces, trials have to be made in order to verify the feasibility of the electrolytic (ionic) connection. Hydrophobic treatments may not result into correct contact.

There must be complete electrolytic contact between the sensor and the concrete surface. Any local deformation or insulating layer must be avoided or removed by grinding or choosing another location. Small deformations in the surface can be, if needed, "ironed out" by using additional sponges.

In case of excessive superficial chloride contamination or very conductive concrete surface layer a correct measurement may be difficult This can be checked by measuring concrete resistivity. If the values obtained are below $1 \mathrm{k} \Omega \cdot \mathrm{cm}$ an unacceptably high conductive concrete surface can be expected. It is then recommended to clean the surface from salts and to wash the contact sponge 
(6.1.3) very well with uncontaminated water. In very wet concrete, it may happen that measurements are very unreliable (too high corrosion rates or improper functioning). In these cases, the method suggested for measuring in submerged structures (chapter 5.2) or the use of a large auxiliary counter electrode (chapter 5.4) may be the only feasible methods.

Measurements can be performed in cracked concrete. However, locations with major voids, delaminations or large cracks $(>1 \mathrm{~mm})$ within the concrete must be avoided, in particular if the concrete is wet, because these defects may cause the signal to deviate from the required electrolytic path, resulting in erroneous readings.

\subsubsection{Placement and fixation of the auxiliary sensor in} the measurement location

The auxiliary sensor must be located preferentially directly over a rebar of known diameter, either a single bar or at a crossover. Metallic (electronic) short circuits between this sensor and the bar caused by tie wire, nails etc. must be avoided as these will invalidate the reading.

The sponge beneath the auxiliary sensor has to be well wetted in order to enable an adequate correct electrolytic contact with the prewetted concrete surface.

If the surface is vertical or horizontal overhead, the auxiliary sensor has to be secured with appropriate fixing tools (plastic straps, screws or some kind of pressing devices).

The steel area below the counter electrode or that area which will be polarized during the measurement has then to be calculated taken into account whether two or more bars

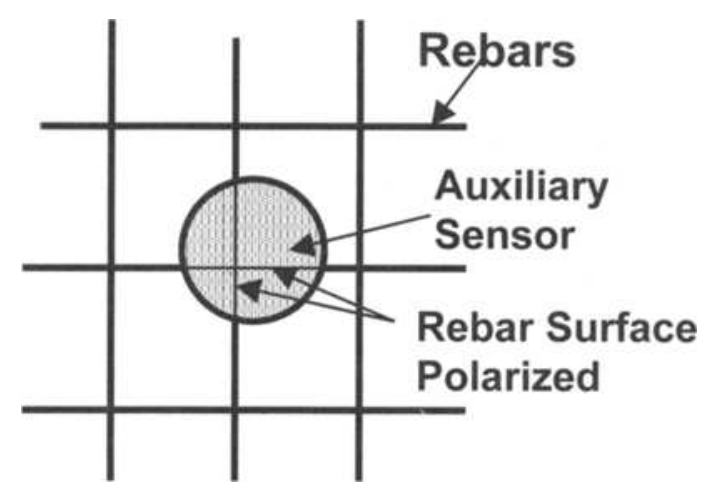

Fig. 21 - The metallic area to be taken into account is that facing the auxiliary sensor.

intersect in that area (see Fig. 21).

\subsubsection{Connection between equipment and reinforcement}

In order to complete the measurement circuit, an electrical connection has to be made between the equipment and the reinforcement. A window to the rebar must be opened by coring, excavation or a connection through an exposed steel connected to the reinforcement and through a cable attached to the rebar. The rebar must be cleaned (for instance by brushing with a metallic brush or by means of a screw) to ensure a good electrical contact.

In order to avoid opening of several holes to have electrical contact with the reinforcement network, it is necessary to check the electrical continuity between rebars. If the reinforcement is electrically continuous then this connection can remain in place for testing at other points on the same span or concrete member. Otherwise, the connection must be moved from bar to bar for each additional test point. The checking is most accurately done by exposing two or more rebars across the structure and measuring the potential difference between them with a high impedance voltmeter (as used for half cell measurements). If the potential difference is less than $1 \mathrm{mV}$, then continuity is likely, if it is greater than $3 \mathrm{mV}$, continuity is unlikely, if it is between $1 \mathrm{mV}$ and $3 \mathrm{mV}$, continuity is uncertain. In addition, the DC resistance has to be measured, and then the leads reversed and measurement repeated or the $\mathrm{AC}$ resistance tested. The resistance should be less than $1 \mathrm{ohm}$ in all cases.

It is essential that there is good electrical continuity between the rebar connection and the steel being measured. Reasons for discontinuity include construction joints with separated rebar cages, excessive corrosion and light reinforcement content. If discontinuities are found then it may be necessary to make regular rebar connections rather than just one or two.

\subsubsection{Execution the measurement}

A correct connection with the reinforcement may be verified by checking the stability of the corrosion potential, $\mathrm{E}_{\text {corr. }}$ Its stability is necessary to assure a correct measurement of the voltage shift after (applying) the current. The stability is insufficient if the reading fluctuates more than $0.5 \mathrm{mV}$ every 5 seconds.

After switching the device on, the measurement has to be carried out until completion of the testing time. If repetition of the measurement is necessary, it has to be taken into account that the time interval between consecutive measurements shall be long enough to allow the corrosion potential to recover its stability.

Finally, the auxiliary sensor has to be removed and a new location identified.

\subsection{Source of errors in the practical measurement}

There are several sources of error. Some of them can be detected by unsuitability or instability of the $\mathrm{E}_{\mathrm{corr}}$. The most frequent can be due to:

a) A lack of correct electrical contact between the equipment and the reinforcement. In order to avoid this, the bar has to be well cleaned by removing all rust. A surface with metallic bright appearance is the suitable finishing to make proper contact with the plug of the equipment.

b) A lack of correct electrolytic contact between auxiliary sensor and concrete surface. Several factors may be the reason:

- The concrete surface is still too dry. Longer and more efficient wetting has to be tried.

- Contamination of the sponge by salts or by the liquid of the reference electrode. Removal of salts from the concrete surface and washing of the sponge are needed. As well cleaning of the reference electrode membrane.

A lack of moisture in the reference electrode membrane due to long time of storage. Wetting of the membrane is necessary to re-establish the electrolytical connection.

c) Too wet concrete surfaces. Superficial electrolytical shortcircuit (too conductive concrete surface) is produced. 
Cleaning of salts or removing of liquid water on the surface is necessary. In extreme cases the concrete has to be considered as in submerged conditions.

d) The existence of stray currents. It is very difficult to eliminate their influence due to the instability induced in $\mathrm{E}_{\text {corr }}$. The sensorized confinement method may be the only possibility of measuring, preferably by moving the auxiliary sensor around to measure with the two confining reference electrodes in all directions.

e) Care has to be taken in interpreting which bar layer is corroding. The best is to place the auxiliary sensor nearer to the layer expected to be corroding. If the first layer is corroding, it shields the applied current from arriving at deeper positions. If the first layer is passive and the second corroding, an intermediate value between passivity and corrosion will be recorded.

\subsection{Frequency of measurements}

Two types of frequencies have to be considered: the geometrical (how many readings for the same structure) and the temporal (whether a single visit is enough or a sequence of several is necessary).

\subsubsection{Geometrical frequency}

With regard to the geometrical frequency, the structure has to be subdivided in lots (grouping) considering: a) the aggressiveness of the environment, b) the structural typology and c) the aim of the inspection. The groups of structural elements will be then treated statistically in order to obtain a representative value for each element group or, on the opposite, they will be mapped to obtain a pattern of the corrosion current.

\subsubsection{Temporal frequency}

The temporal frequency will depend on the aim of the inspection. If this is only the identification of the corroding zones or to evaluate the effectivity of a repair work, a single visit may be enough. The lack of measurements along the time is recommended to be balanced by taken a larger possible number of readings at different locations of the structure (geometrical frequency), selected regarding several degrees of apparent damage or exposure aggressivity.

In all cases, plotting of the results in a $I_{\text {corr }}-\rho$ graph as explained in chapter 8.2 .3 will help to evaluate the validity of the results obtained.

When the appraisal of the load-bearing capacity of the structure is aimed at, then, in order to obtain a sufficiently accurate representative value of the corrosion rate, $I_{\text {corr }}^{R E P}$, it is necessary to perform several measurements along, at least, a whole year following the seasonal exposure variations (see paragraph 8.2.5).

\section{DATA PRESENTATION REPORT}

Basically, the data presentation report has to contain (relating only to the corrosion current):

a) The date of testing

b) Description of the measurement site (location and visual aspect) c) The record of the weather conditions at the moment of the measurements ( $\mathrm{T}, \mathrm{RH}$ and rain). If possible, the weather of the previous week should also be included.

d) The grid space used

e) Groups (lots) if made. Criteria used for identifying the lots

f) The steel reinforcement area used to calculate the $R_{p \text {, true }}$

g) The method of measurement used.

h) Graph of $I_{\text {corr }}-\rho$ if recorded

i) The $E_{\text {corr }} R_{e}$ and $I_{\text {corr }}$ results recorded; morphology of attack: pitting or uniform.

j) Cover depth and carbonation; chloride profile.

Concerning the presentation of $\mathrm{I}_{\text {corr }}$ values themselves, either histograms, simple graphs or iso- $\mathrm{I}_{\text {corr }}$ maps can be used. The maps may be coloured by giving a colour to the four ranges of Table 1.

\begin{tabular}{|c|c|c|}
\hline \multicolumn{3}{|c|}{$\begin{array}{c}\text { Table } 1 \text { - Ranges of corrosion current values } \\
\text { related to the significance in terms of service life } \\
\text { of the reinforcement }\end{array}$} \\
\hline $\mathrm{I}_{\text {corr }}\left(\mu \mathrm{A} / \mathrm{cm}^{2}\right)$ & $\mathrm{V}_{\text {corr }}(\mathrm{mm} / \mathrm{y})$ & Corrosion level \\
\hline$\leq 0.1$ & $\leq 0.001$ & Negligible \\
$0.1-0.5$ & $0.001-0.005$ & Low \\
$0.5-1$ & $0.005-0.010$ & Moderate \\
$>1$ & $>0.010$ & High \\
\hline
\end{tabular}

The $I_{\text {corr }}-\rho$ graph (Fig. 25) is also a useful tool for the interpretation/evaluation and enables the extrapolation for predicting the maximum corrosion current, $I_{\text {corr, } \max }$.

Additionally, a statistical treatment may be made, either for each individual lot or with the whole set of values. Simple cumulative or differential statistical analysis may help to identify corroding and non corroding zones or to establish the averaged $I_{c o r r}^{R E P}$ to be used for making predictions of future evolution of the damage to help in the assessment. Cross relations between $\mathrm{I}_{\mathrm{cor}}, \rho$ or chloride contents at the level of the reinforcing steel will also be of benefit.

\section{INTERPRETATION AND USE OF I $_{\text {orr }}$ RESULTS}

\subsection{Definitions}

For a correct interpretation of the $I_{\text {corr }}$ results it is required that some variables will be defined:

\subsubsection{Representative value of $I_{\text {corr }}$ or $V_{\text {corr }}$}

A representative value of $\mathrm{I}_{\text {corr }}$ or $\mathrm{V}_{\text {corr }},\left(I_{\text {corr }}^{R E P}, V_{\text {corr }}^{R E P}\right)[55$, $59,60]$ is defined as an averaged value along a certain period of time for every single measurement location. The $V_{\text {corr }}^{R E P}$ values may then be implemented into structural calculation models of the residual load-bearing capacity.

The averaged value can be obtained in two manners [64]: a) by calculating the arithmetic mean of $I_{\text {corr }}$ values registered during a period of time and performed during seasons of practical relevance ( $n$ is the total number of measurements and should be higher than 4). 


$$
I_{\text {corr }}^{R E P}=\frac{\sum_{0}^{n} I_{\text {corr }}}{n}
$$

b) by averaging a value $I_{c o r r}^{R E P}$ measured on-site, $\mathrm{I}_{\text {corr, single, }}$ with another one $I_{\text {corr }}$ lab, obtained in cores drilled from the structure and conditioned in the laboratory to a certain water saturation degree:

$$
I_{\text {corr }}^{R E P}=\frac{I_{\text {corr }, \text { lab }}+I_{\text {corr }, \text { sing }}}{2}
$$

\subsubsection{Penetration of attack, $P_{x}$}

The penetration of attack, $P_{x}$ [63] (Fig. 21) at a certain moment of the propagation period $t_{p}$, is the loss in radius of the bar produced at a certain $t_{p}$. It is also expressed as "corrosion penetration damage function" when used for further calculation of the structural performance. It can be calculated provided the initiation time is established, from the gravimetric loss divided by the density of the metal and the total area of attack which gives the equivalence given in paragraph 3.5: an averaged corrosion current density of $1 \mu \mathrm{A} / \mathrm{cm}^{2}$ is equivalent to an averaged penetration rate of $11.6 \mu \mathrm{m} /$ year.

It may also be obtained by integration of the corrosion current, $I_{\text {corr }}$ (expressions (9) and (10)) or corrosion rate, $V_{\text {corr }}$, values until $t_{p}[1]$ by means of the expression:

Uniform corrosion:

$P_{x}(\mathrm{~mm})=0.0116 I_{\text {corr }}^{R E P} \cdot t_{p}=V_{c o r r}^{R E P} \cdot t_{p}$

where $t_{p}$ is the propagation period [year].

\subsubsection{Pitting factor, $\alpha$}

The pitting factor, $\alpha,[41]$ or corrosion concentration factor, represents the compensation of the relative error due to the differences in actual size of corroding area due to localized attack. It results from dividing the maximum pit depth (localized attack), $\mathrm{P}_{\text {pit }}$, obtained by visual inspection by the attack penetration averaged to the full circumference, $P_{x}$, (see Fig. 23):

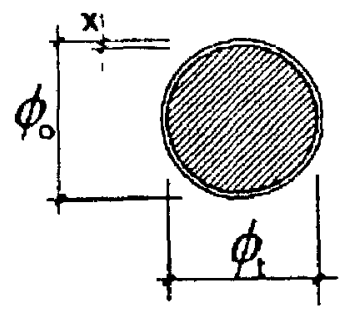

\section{HOMOGENEOUS CORROSION}

Fig. 22 - Attack penetration: case of uniform corrosion.

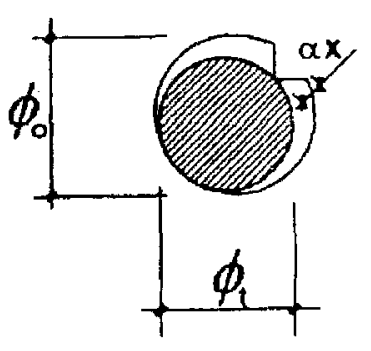

PITTING $[\alpha \leqslant 10]$
Fig. 23 - Residual cross section in the case of pitting (localized attack). $[\alpha \cong 10]$.
$\alpha=\frac{P_{p i t}}{P_{x}}$

\subsubsection{Maximum pit depth, $P_{p i t}$}

The maximum pit depth, $P_{\text {pit }}$ (Fig. 23) represents the local maximum loss in bar diameter. It is calculated from the expression (11) multiplied by $\alpha$ :

$P_{p i t}=P_{x} \cdot \alpha=V_{c o r r}^{R E P} \cdot t_{p} \cdot \alpha=V_{p i t} \cdot t_{p}$

Therefore, when the attack is localized, the pitting corrosion rate $V_{\text {pit }}(\mathrm{mm} / \mathrm{y})$ can be calculated by multiplying the uniform corrosion rate $V_{\text {corr }}$ by $\alpha$.

In the case of steel embedded in concrete $\alpha$ has been found to vary from 3 to $10[41,61,63]$. The value of 3 can be used for the case of several scattered and coarse pits, while the value of 10 applies to very localized pitting corrosion. In the case of uniform corrosion $\alpha$ takes a value of 2 to represent the uniform loss in diameter around the bar (Fig. 22).

Figs. 22 and 23 also indicate the recommended residual cross section (dashed circle within the original bar cross section) to be considered when implementation of the residual diameter into structural models is going to be made.

\subsubsection{Rebar diameter, $\Delta \emptyset_{t}$}

The loss of rebar diameter, $\Delta \emptyset_{\mathrm{t}}$, can be calculated from expression [63]:

$\Delta \emptyset_{\mathrm{x}}(\mathrm{mm})=\emptyset_{\mathrm{o}}-\emptyset_{\mathrm{t}}=\emptyset_{\mathrm{o}}-\mathrm{P}_{\mathrm{x}} \cdot \alpha$

Where $\emptyset_{0}$ is the initial diameter and $\Delta \emptyset_{\mathrm{x}}$ is the diameter loss after a certain period t of corrosion. The value of $\alpha$ is equal to 2 (Fig. 22) for uniform corrosion and for localized corrosion (Fig. 23) may vary from 3 to 10 . The value of 10 is usually taken in order to have conservative predictions.

\subsection{Interpretation of corrosion rate results}

\subsubsection{Classification of corrosion rate results}

Values of $\mathrm{I}_{\text {corr }}$ below $0.1 \mu \mathrm{A} / \mathrm{cm}^{2}$ indicate negligible corrosion from a practical point of view, and therefore, the steel reinforcement can be classified as "passive". The range between $0.1-0.2 \mu \mathrm{A} / \mathrm{cm}^{2}$ can be considered the transition region between passive and active corrosion. This range is due to the inherent uncertainty of Stern's formula which assumes an intrinsic error factor of two.

Expressing $I_{\text {corr }}$ in $\mu \mathrm{A} / \mathrm{cm}^{2}$, and $V_{\text {corr }}$ in $\mathrm{mm} / \mathrm{y}$, the following classification has been established $[1,10,63]$.

Values of $I_{\text {corr }}$ above $1 \mu \mathrm{A} / \mathrm{cm}^{2}$ are seldomly measured in real size structures and values higher than $10 \mu \mathrm{A} / \mathrm{cm}^{2}$ have almost never been recorded. In

Table 2 - Ranges of corrosion current values related to the significance in terms of service life of the reinforcement

\begin{tabular}{|c|c|c|}
\hline $\mathrm{I}_{\text {corr }}\left(\mu \mathrm{A} / \mathrm{cm}^{2}\right)$ & $\mathrm{V}_{\text {corr }}(\mathrm{mm} / \mathrm{y})$ & Corrosion level \\
\hline$\leq 0.1$ & $\leq 0.001$ & Negligible \\
$0.1-0.5$ & $0.001-0.005$ & Low \\
$0.5-1$ & $0.005-0.010$ & Moderate \\
$>1$ & $>0.010$ & High \\
\hline
\end{tabular}


consequence the most common values for actively corroding rebars range from 0.1 to $1 \mu \mathrm{A} / \mathrm{cm}^{2}$.

\subsubsection{Relation between corrosion current and corrosion potential values}

No unambiguous mathematical relationship has been found between the corrosion potential, $\mathrm{E}_{\text {corr }}$, and $\mathrm{I}_{\text {corr }}$ as is shown in Fig. 24 where results of numerous inspections are presented. This lack of a clear correlation has been attributed to the fact that both parameters respond differently to the same variables. Particularly moisture (oxygen availability), temperature and concrete resistivity values seem to affect both electrochemical parameters, however in different proportion.

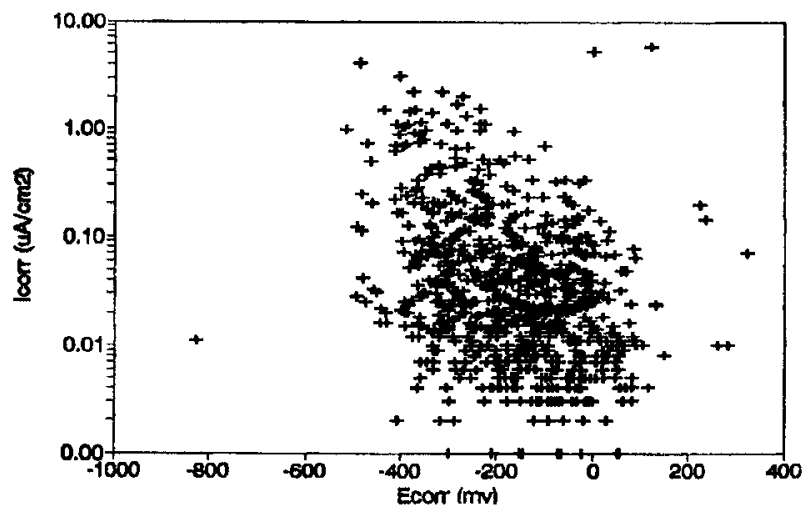

Fig. 24 - Plot of $\mathrm{I}_{\text {corr }}$ versus $\mathrm{E}_{\text {corr }}$. A general correlation does not exist.

On the other hand, it has been noticed that rust composition has an influence on the $E_{\text {corr }}$ values [46-48] and thus, for the same corrosion rate a different aging of the rust (proportion $\mathrm{Fe}^{+2} / \mathrm{Fe}^{+3}$ ) will induce different $\mathrm{E}_{\text {corr }}$ values.

\subsubsection{Relation between corrosion current and resistivity (I corr $_{\text {- } \rho \text { graph) values }}$}

On the other hand, $I_{\text {corr }}$ values present a better relationship with the concrete resistivity values, as is

\section{CORROSION CURAENT ARESISTWITY (MOISTURE) DIAGRAM}

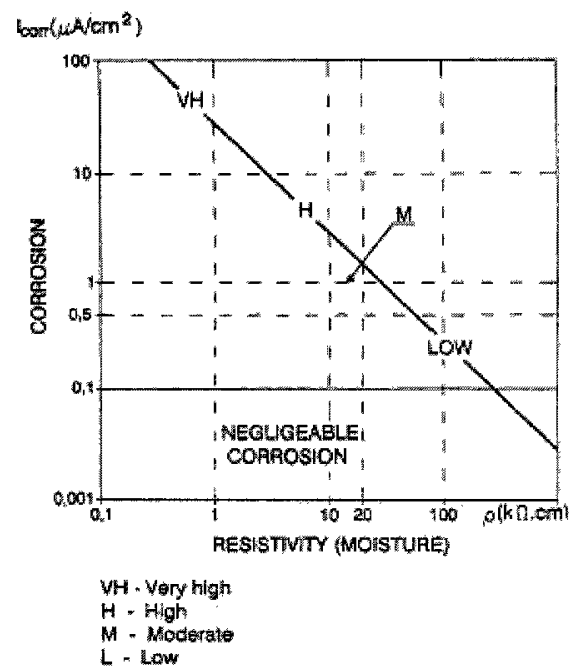

Fig. 25 - Plot of $I_{\text {corr }}$ values versus concrete resistivity The diagonal line indicates the relation usually found between these two parameters. The corrosion regions are marked following Tables 1 and 2 .

\begin{tabular}{|c|c|}
\hline $\begin{array}{c}\text { Table } 3 \text { - Resistivity ranges related to the } \\
\text { risk of corrosion }\end{array}$ \\
\hline $\begin{array}{c}\text { Concrete resistivity } \\
(\mathrm{k} \Omega \cdot \mathrm{cm})\end{array}$ & Corrosion risk \\
\hline$>100$ & Negligible \\
-100 & Low \\
$10-50$ & Moderate \\
$<10$ & High \\
\hline
\end{tabular}

presented in Fig. 25 [58]. Although a wide scatter is registered, a certain relation between both variables seems to exist. This relation follows the general trend of the expression:

$\mathrm{I}_{\text {corr }} \cong 3 \cdot 10^{4} \cdot \rho$

with $I_{\text {corr }}$ expressed in $\mu \mathrm{A} / \mathrm{cm}^{2}$ and $\rho$ in $\mathrm{ohm} \cdot \mathrm{cm}$.

This empirical relation results from the fact that concrete resistivity is a direct function of the moisture content of the concrete and more precisely, from its degree of water saturation. A ranking of resistivity values has been established [58] which is shown in Table 3:

An $\mathrm{I}_{\text {corr }}-\rho$ graph can be established from Tables 2 and 3.

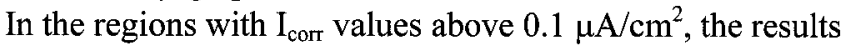
should follow a parallel slope to the main line for different values of $\rho$.

\subsubsection{Evolution with time of corrosion current values}

When the steel is passive, the $I_{\text {corr }}$ values usually remain below $0.1 \mu \mathrm{A} / \mathrm{cm}^{2}$, however just after mixing or with prerusted rebars, the $I_{\text {corr }}$ values may be significantly higher without indicating a significant loss of base metal.

When the carbonation front or the chloride threshold reaches the steel surface, local depassivation occurs with a noticeable increase in the $I_{\text {corr }}$ values [10]. After depassivation, the $I_{\text {corr }}$ may vary in function of the intrinsic variability of any corrosion process or to extrinsic factors (exposure conditions or external weather).

Usually, depassivation does not occur instantaneously but takes some time during which events of activation/repassivation occur until the whole perimeter of the bar has become depassivated. During depassivation the corrosion is always produced locally, either due to the generation of pits or to the fact that the carbonation front has reached the upper surface of the rebar only. Then the initial pits or corroding zones may grow or repassivate and new corroding zones may generate, until the advance of the carbonation front finally encloses the whole perimeter.

In consequence the values of $I_{\text {corr }}$ during the depassivation process may not remain constant, but vary significantly over time and the location of the structure. When fully depassivated, the corrosion process develops by generating iron oxides which may induce cracking of the cover It is important to note that cracking not always induces an acceleration of the corrosion process because of the fact that cracks may result in a quicker drying. In consequence, the whole process is in continuous evolution and the corrosion rate may also vary from place to place and time to time.

$I_{\text {corr }}$ may as well change due to the weather conditions $[59,60]$. The degree of water saturation $S_{w}$ is the main factor influencing $I_{\text {corr }}$, together with temperature. The 
degree of water saturation, $S_{w}$, is a consequence of the rain periods (in concrete non sheltered from rain) or of the precise conditions in $\mathrm{T}$ and $\mathrm{RH}$ in sheltered concrete. The knowledge of these climatic events is of importance to interpret the values of $I_{\text {corr }}$ recorded on-site. The $S_{\mathrm{w}}$ can be determined by also measuring the concrete resistivity (graph $\mathrm{I}_{\text {corr }}-\rho$ ) or by weighing a concrete core taken from the structure in the same moisture conditions as the measurement points.

\subsubsection{Calculation of a representative value of $I_{\text {corr }}$}

The natural scatter in the evolution of $\mathrm{I}_{\text {corr }}$ values in time and place does not prevent the obtainment of a representative value to be used for assessing the condition of the structure, but calls for rules or methodologies for its calculation $[61,62]$.

The accuracy in the calculation of a $I_{\text {corr }}^{R E P}$ will depend on the number of individual $\mathrm{I}_{\mathrm{corr}}$ measurements recorded. In on-site measurements, there are basically three possibilities: 1) continuous monitoring by embedded or permanent sensors, 2) the recording of several values at equal time intervals along a year period and 3) the obtainment of single isolated values of $\mathrm{I}_{\text {corr }}$. The general procedure is shown in Fig. 26.

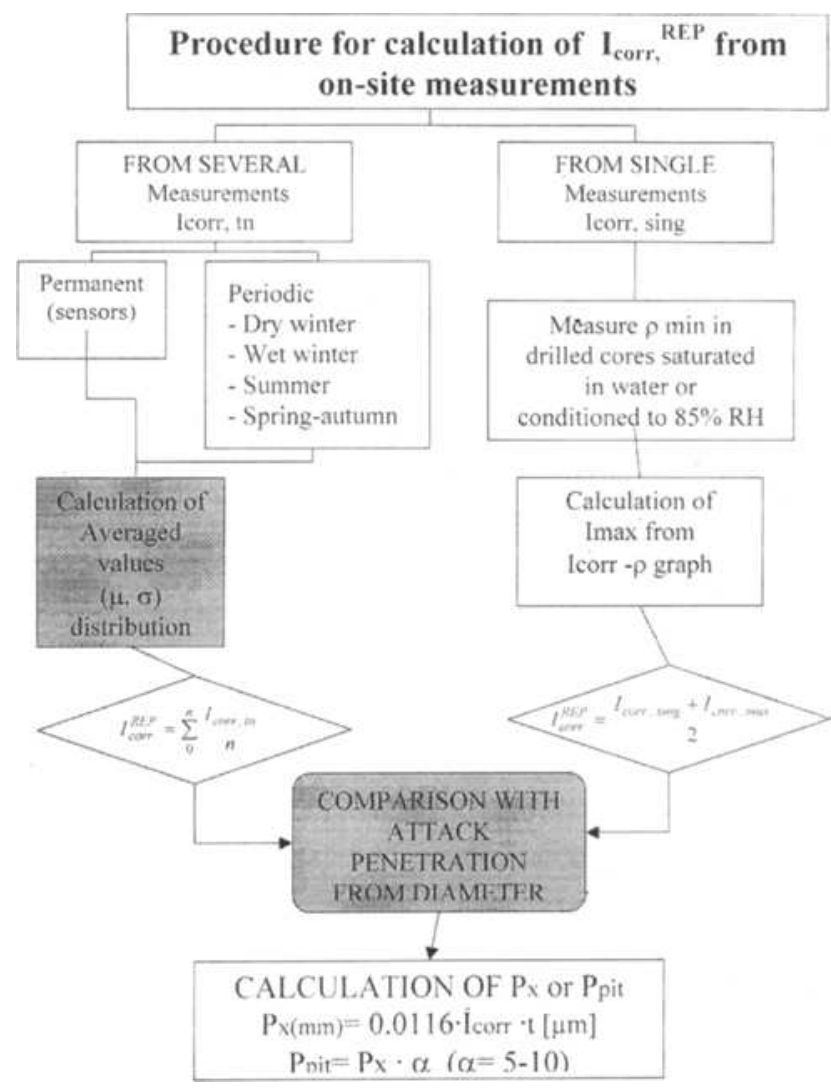

Fig. 26 - General procedure for obtaining the Representative $I_{\text {corr }}$ when the drilled cores in the right branch (single measurements on-site) do not have pieces of rebar.

\subsubsection{Continuous monitoring}

When continuous recording of data from permanently installed sensors is possible, $I_{c o r r}^{R E P}$ can be obtained from the averaging of the $I_{\text {corr }}-t$ curve as indicated by expression (9) or (10).
Due to the daily temperature cycles, it is recommended to obtain at least 2 values per day, related to the maximum (mid-day) and minimum (mid-night) expected temperature values. Four values per day seems to be an optimum in order not to overload the recording, but enables registration during the most important weather events (e.g. rainfall).

\subsubsection{Discontinuous measurements}

In the case of non-permanent installations, it is recommended to take several measurements along a year period. A minimum of 4 readings per year is recommended. They will be taken during the most extreme climatic conditions which, for the sake of the corrosion process, may be defined in the following manner:

1. Dry periods with low temperatures.

2. In the periods of lower temperatures after several consecutive events of raining (humid period).

3. Dry periods and high temperatures.

4. Periods with high temperature but after long rainfall (humid and hot periods).

Measurements performed during these periods will enable the recording of nearly minimum and maximum values of $I_{\text {corr }}$ exhibited by the particular structure at the measurement points. The representative $I_{\text {corr }}^{R E P}$ will be obtained through expression (9). Its value will be more accurate as the number of measurements, $n$, increases. Not only the mean value, but also the standard deviation may be used for making reliable predictions (chapter 8.3.3.1.)

\subsubsection{Single measurements}

When only one isolated measurement can be performed, obtaining a representative $\mathrm{I}_{\text {corr }}$ is more uncertain. In order to interpret the readings in the most accurate way, the procedure recommended is based on the averaging of the site measurements with those obtained in cores drilled from the structure. In these cores either the corrosion rate of embedded pieces of rebar can be averaged with the site values, or the $I_{\text {corr }}$ values can be obtained through the relation between concrete resistivity and $\mathrm{I}_{\text {corr }}$ measured in the cores.

In the most normal case that the cores have not pieces of rebars, the procedure recommended is shown in Fig. 27. In this figure it is represented by the line AB the averaged general relation between $I_{\text {corr }}$ and $\rho$ when plotted on a $\log -$ log diagram (Fig. 25). The linear relation presents a slope of -1 (Equation (15)). As a consequence, the procedure proposed is as follows:

- After having measured on-site the concrete resistivity and corrosion current, cores should be drilled close to the measurement points. Cores are returned to the laboratory. Then they are conditioned to a moisture content corresponding to $85 \% \mathrm{RH}$ (for structures sheltered from rain) or to water saturation after being air/vacuum (for non sheltered or submerged ones). When the cores are equilibrated to the moisture conditions their minimum electrical resistivity, $\rho_{\min }$ is measured.

- The cores should be in such a condition that they are representative of the actual condition of the structure (no additional cracks/damage due to drilling are allowed). Preferentially, the concrete cores to be investigated in the laboratory should be retrieved at the locations where the actual measurements on site were performed. 


\section{CORROSION CURRENT-RESISTIVITY (MOISTURE) DIAGRAM}

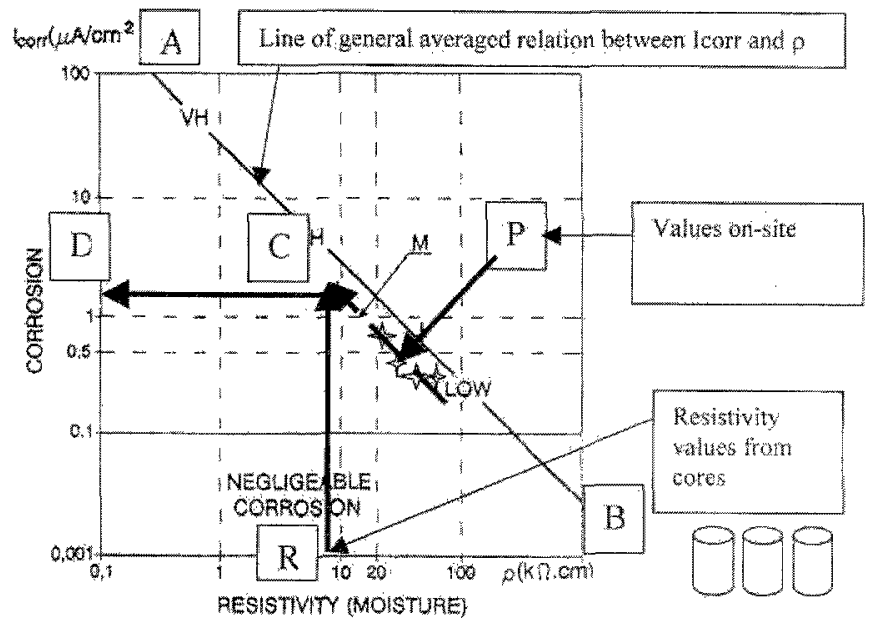

VH. Vary high

$H=$ High

M. Moderate

L. Low

Fig. 27 - Procedure suggested for averaging results measured in a single visit on site with values deduced from resistivity measured in drilled cores conditioned in the laboratory.

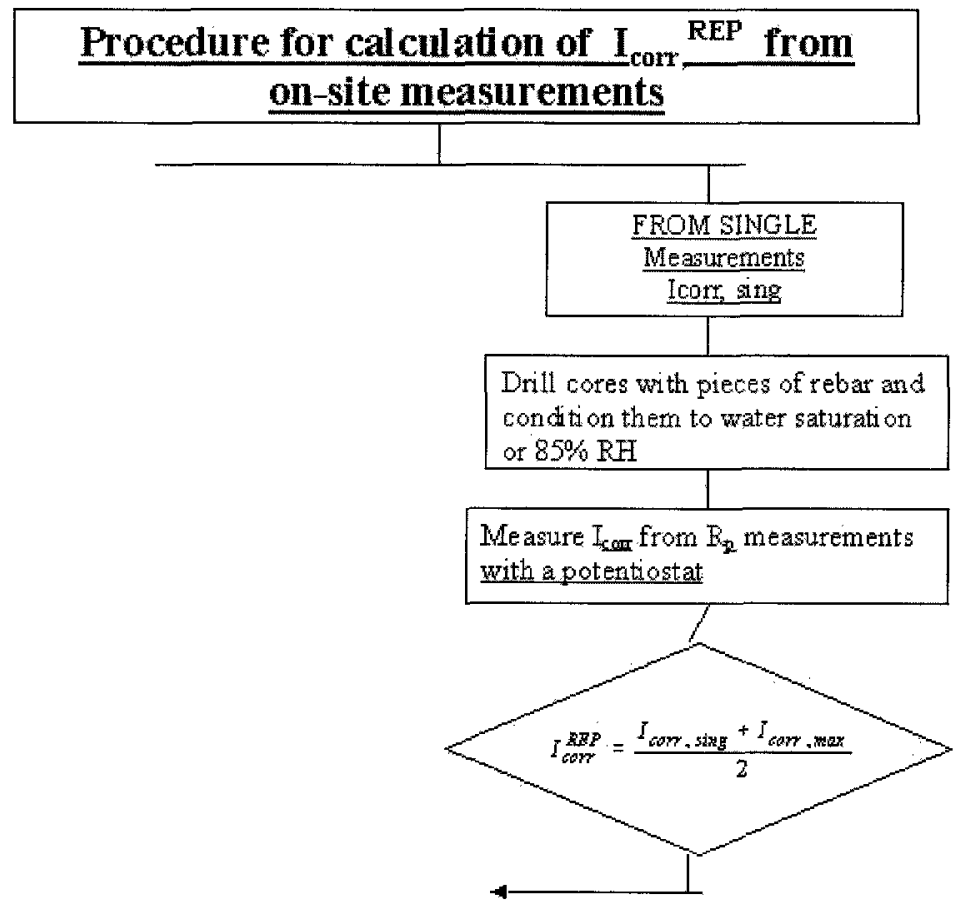

Fig. 28 - Alternative to the general procedure shown in Fig. 27 for the case that the drilled cores in the on-site single measurements have pieces if rebar embedded.

Then, the set or clusters of values of $I_{\text {corr }}$ and - $\rho$ registered on-site are plotted on the graph (points $\mathbf{P}$ on Fig. 27) and the $\rho_{\min }$ measured in the cores is identified in the graph (point $\mathrm{R}$ ). Then a regression line is drawn through the measured, $P$, values. This line is extrapolated to reach the vertical of $R\left(\rho_{\min }\right)$ (point $C$ ) which is then extrapolated to $D$, to obtain the $I_{\text {corr,max }}$ (maximum) value coherent with the minimum resistivity values of the cores.

- An alternative derived from this methodology is given in Fig. 28. It consists in drilling concrete cores containing

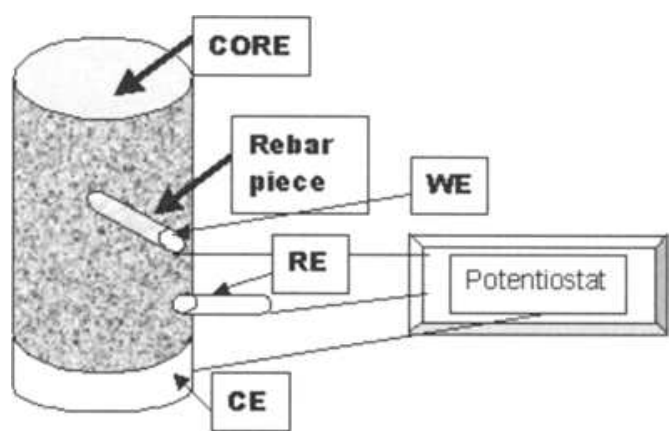

Fig. 29 - Core with a piece of rebar that can be used to obtain the $I_{\text {corr, max }}$ value through the $R_{p}$ determination after conditioning the core in the laboratory at a predetermined humidity $(85 \% \mathrm{RH}$ or water saturated).

a piece of rebar (see Fig. 29). If the cores themselves contain the steel bar, the use of the $\rho-I_{\text {corr }}$-relationship will not be necessary. In the case of cores with reinforcements, the cores would be as well conditioned in the laboratory to the maximum selected humidity and $\mathrm{I}_{\text {corr }}$ would be measured directly in the pieces of rebar in the core by means of a potentiostat and an external counter and reference electrodes. The actual condition of the embedded steel section should be checked after the measurements and characterized by type of attack (uniform, localised, penetration depth). The real diameter loss should be measured as well after removing the rust.

In summary, when only a singe visit on site is feasible the value of $I_{\text {corr }}^{R E P}$ is calculated by taking two set of values: those measured on site $\left(I_{c o r r}\right.$, single $)$ and those measured in the laboratory in cores drilled from the structure. That is, from the average of the single on-site values, $\mathbf{I}_{\text {corr, single }}$ and the maximum value achieved under laboratory conditions, $\mathbf{I}_{\text {corr, max }}$, for the particular condition selected ( $85 \% \mathrm{RH}$ or saturated) [62]. The cores drilled may or not have embedded pieces of rebar. If they have, the $I_{\text {corr, max }}$ can be measured directly by means of a potentiostat. If the cores do not contain isolated pieces of rebar, the $I_{\text {corr }}-\rho$ graph must be used in order to deduce $I_{\text {corr, } \max }$ from $\rho_{\min }$.

$$
I_{\text {corr }}^{R E P}=\frac{I_{\text {corr }, \operatorname{sing}}+I_{c o r r, \max }}{2}
$$

However, caution has to be taken if the values are to be implemented into structural models for the calculation of the load carrying capacity. The lack of measurements along the different seasons should be compensated with the most practically possible larger sampling in different locations of the structure as was indicated in paragraph 6.7 . 


\subsubsection{Calibration by measurement of the diameter loss of the reinforcement}

Whatever the method used for obtaining a representative $I_{\text {corr }}^{R E P}$ value it is convenient to calibrate it with measurements of the real penetration of attack, $P_{x}$. This can be made from visual inspection of the steel bars through expressions (11, 12 and 13).

However, when the corrosion attack is only very slight (superficial), the measurement of a diameter decrease may be very inaccurate. In such cases, a more accurate, although destructive method, is the measurement of the weight loss of a small portion of the rebar. That is, cutting a small part of the bar and removing the rust oxides by proper cleaning. The weight of the bar, $\mathrm{W}_{\mathrm{f}}$, gives the average penetration of attack, $\mathrm{P}_{\mathrm{x}}$ (expression (11)) by using the following expression:

$$
\begin{aligned}
& \pi r_{i}^{2} L \delta=W_{f}+\pi L \delta\left[r_{i}^{2}-\left(r_{i}^{2}+P_{x}^{2}-2 r_{i} P_{x}\right)\right] \\
& =T T L . . \delta P_{x}\left(2 r_{i}-P_{x}\right)
\end{aligned}
$$

where, $r_{i}$ is the initial nominal radius, $L$ is the length of the cut-piece of reinforcement, $\mathrm{W}_{\mathrm{f}}$ the final (actual) weight and $\delta=7.85$, the theoretical iron density.

A more accurate result can be obtained if $\delta$ is measured by weighing and measuring the volume of an identical unrusted piece of the same reinforcement.

Concerning the location of these measurements of the penetration depth, if possible, the points of measurement should be selected close to those where the $I_{\text {corr }}$ have been recorded. A distinction has to be made between uniform and localized corrosion $\left(\mathrm{V}_{\text {corr }}\right.$ or $\left.\mathrm{V}_{\text {pit }}\right)$.

\subsection{Use of corrosion rate results}

As was mentioned before, the $\mathrm{I}_{\text {corr }}$ values can be used for the following different purposes:

\subsubsection{Identification of actively corroding zones}

These areas will be deduced from the delimitation of zones with different $I_{\text {corr }}$ values taken Table 1 as indicative of corrosion levels.

Corrosion rate maps will help to identify the corroding zones in the same manner as potential mapping. Fig. 20 shows an example.

As was mentioned in paragraph 8.2.4, when analyzing the corrosion rate data, account has to be taken regarding: a) the particular circumstances of evolution of the whole electrochemical process and b) the prevailing moisture conditions of the concrete at the measurement location and time.

\subsubsection{Evaluation of the effectivity of repair techniques}

In order to evaluate the effectivity of a repair technique, measurements prior to and after the treatment should be carried out.

Concerning the measurements after the repair, attention has to be paid to the different electrochemical conditions that a repair may induce in the structure involving evolution of the macrocell activity.

In the case of the application of inhibitors, care has to be taken on the time elapsed between treatment and $I_{\text {cor }}$ measurements in order to allow the inhibitor to become effective. More than one single measurement after the treatment is recommended and special care has to be taken to obtain representative results before and after inhibitor treatment, taking changes in temperature and moisture condition into account.

In the particular case of non-permanent electrochemical repair techniques, particularly realkalization and chloride extraction, sufficient time for recovery of the electrochemical potential to the natural values has to be allowed for, because if the rebar is polarized the current determined is not related to the true corrosion current $\mathbf{I}_{\text {corr }}$.

\subsubsection{Implementation into structural calculations (damage functions)}

The corrosion process results into four main detrimental consequences [63-68] (Fig. 30):

1. Reduction of bar cross section;

2. Reduction of steel ductility;

3. Cracking of concrete cover;

4. Reduction of steel/concrete bond (composite effect).

The degradation of these structural characteristics call for the establishment of several damage functions able to link the degree of deterioration or cross section loss, $P_{x}$, with the loss of structural load-bearing capacity.

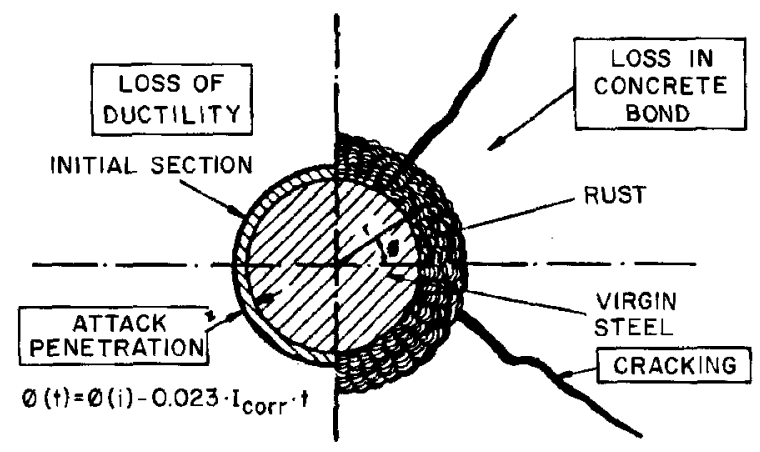

Fig. 30 - Consequences of rebar corrosion which lead into the decrease in load-bearing capacity of the structure.

\subsubsection{Calculation of loss in rebar cross section (damage function of attack penetration, $P_{x}$ )}

The primary damage function $[42,57,63]$ to be obtained from $I_{\text {corr }}$ values recorded on site is that concerning the penetration depth $\mathrm{P}_{\mathrm{x}}$ (definitions in paragraph 8.1). Attention has to be paid on whether the corrosion attack is localized (expression (13)).or rather uniform. The value of $\mathrm{I}_{\text {corr }}$ to be introduced in these expressions is $I_{\text {corr }}^{R E P}$.

As was described in chapter 8.2.5, $I_{\text {corr }}^{R E P}$ to be used for calculating the future evolution of the damage or of the residual load-bearing capacity, has to be accurately obtained. Either by calculating an average and standard deviation of the $I_{\text {corr }}^{R E P}$ from several measurements in the case of isolated measurements or by using the actual value recorded in the structure and a second value obtained through any of the methods described in 8.2.5.3.

\subsubsection{Implementation into structural models}

Concerning the rest of structural consequences, (cover cracking, decrease in bond, and load-bearing capacity) their particular damage function formulation is out of the scope of the present Recommendation. They can be found in [64-68]. 


\section{SYMBOLS}

B Stern constant [V]

C Electrical capacitance $[\mathrm{F}]$

CE Counter or auxiliary electrode

E Electrical potential [V]

$\Delta \mathrm{E} \quad$ Potential step [V]

$\mathrm{E}_{\text {corr }} \quad$ Corrosion or mixed potential [V]

$\mathrm{i}_{\text {corr }} \quad$ Instantaneous corrosion current density $\left[\mu \mathrm{A} / \mathrm{cm}^{2}\right]$

$I_{\text {corr }} \quad$ Non-uniform instantaneous corrosion current Density $\left[\mu \mathrm{A} / \mathrm{cm}^{2}\right]$

$\Delta \mathrm{I} \quad$ Current step [A]

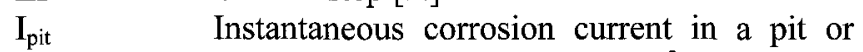
localized corroding spot $\left[\mu \mathrm{A} / \mathrm{cm}^{2}\right]$

$\mathrm{I}_{\text {galv }}$ Galvanic corrosion current between corroding and cathodic zones $\left[\mu \mathrm{A} / \mathrm{cm}^{2}\right.$ or $\left.\mu \mathrm{A}\right]$

$I_{\text {corr,lab }} \quad I_{\text {corr }}$ determined in small specimens with finite reinforcement area $\left[\mu \mathrm{A} / \mathrm{cm}^{2}\right]$

$I_{\text {corr,sing }} I_{\text {corr }}$ determined on site only one time $\left[\mu \mathrm{A} / \mathrm{cm}^{2}\right]$

$\mathrm{I}_{\text {corr,tn }} \quad$ Averaged $\mathrm{I}_{\text {corr }}$ obtained from integrating or averaging several $\mathrm{I}_{\text {corr }}$ measurements obtained during a period of time $t_{n}\left[\mu \mathrm{A} / \mathrm{cm}^{2}\right]$

$I_{\text {corr }}{ }^{R E P} \quad$ Representative- $I_{\text {cort }}$ value $\left[\mu \mathrm{A} / \mathrm{cm}^{2}\right]$

$\mathrm{L}_{\text {erit }} \quad$ Critical length polarized in on-site measurements [cm]

$P_{x} \quad$ Penetration depth of corrosion attack at a certain time $[\mathrm{mm}]$

$\mathrm{P}_{\mathrm{pit}} \quad$ Maximum pit or localized penetration depth [mm]

$\mathrm{R}_{\mathrm{e}} \quad$ Electrical resistance $[\Omega]$

$R_{1}, R_{2}, R_{B} \quad$ Reference electrodes for critical length measurement hold in the auxiliary electrode of potential attenuation method

RE Reference electrode for measurement of $E_{\text {corr }}$

$\mathrm{R}_{\mathrm{p}} \quad$ Polarization Resistance [ $\Omega$ or $\Omega \mathrm{cm}^{2}$ ]

$R_{p, \text { true }} \quad$ True $R_{p}\left[\Omega \mathrm{cm}^{2}\right]$

$\mathrm{R}_{\mathrm{p} \text {,app }} \quad$ Apparent $\mathrm{R}_{\mathrm{p}}\left[\Omega\right.$ or $\left.\Omega \mathrm{cm}^{2}\right]$

$\mathrm{R}_{\mathrm{p}}^{\text {ref }} \quad \mathrm{R}_{\mathrm{p}}$ obtained in a reference reinforced concrete slab for calibrating portable corrosion-ratemeters $\left[\Omega \mathrm{cm}^{2}\right]$

$\mathrm{S} \quad$ Area of the reinforcement to be measured $\left[\mathrm{m}^{2}\right]$

$\mathrm{S}_{\mathrm{A}} \quad$ Anodic or corroding area $\left[\mathrm{m}^{2}\right]$

$\mathrm{S}_{\mathrm{C}} \quad$ Cathodic area $\left[\mathrm{m}^{2}\right]$

$\mathrm{S}_{1}, \mathrm{~S}_{2} \quad$ Reference electrodes to control the confinement in the guard ring auxiliary electrode time or timelife $t$

$t_{i} \quad$ Initiation period in service life model [year]

$t_{p} \quad$ Propagation or corroding period in service

life model [year]

$\mathrm{V}_{\text {corr }}$ Instantaneous corrosion rate $[\mathrm{mm} / \mathrm{year}$ or $\mu \mathrm{m} /$ year]

$\mathrm{V}_{\text {corr }}{ }^{\text {REP }}$ Representative $\mathrm{V}_{\text {corr }}$ value $[\mu \mathrm{m} / \mathrm{year}$ or $\mathrm{mm} /$ year]

$\alpha \quad$ Pitting factor

$\varnothing_{\mathrm{x}} \quad$ Loss in reinforcement diameter after a certain $\mathrm{t}_{\mathrm{p}}[\mathrm{mm}]$

$\varnothing_{0} \quad$ Initial nominal reinforcement diameter [mm]

$\varnothing_{\mathrm{t}} \quad$ Residual reinforcement diameter after a certain $t_{p}[\mathrm{~mm}]$

\section{REFERENCES}

[1] Andrade, C. and González, J.A., 'Quantitative measurements of corrosion rate of reinforcing steels embedded in concrete using polarization resistance measurements', Werkstoffe und Korrosion 29, (1978) 515-519.

[2] Stern, M. and Geary, A.L., 'Electrochemical Polarization: I. A. theoretical analysis of the shape of polarization curves', Journal of Electrochemical Soc. 104 (1) (1957) 56-63.

[3] Stern, M. and Weisert, E.D., 'Experimental observations on the relations between polarization resistance and corrosion rate', Proc. American Society Testing, Materials 59 (1958) 1280.

[4] Feliú, S., González, J.A., Andrade and C., Feliú, V., 'On-site determination of the Polarization Resistance in a reinforced concrete beam', Corrosion (USA) 43 (Sept. 1987) 1-9.

[5] Andrade, C., 'New electrochemical technique for the corrosion measurement in reinforced and presstressed concretes. Use of inhibitor admixtures as prevention method', Ph.D Thesis - Faculty of Chemistry, Complutense Univ. of Madrid, July 1973.

[6] Lorenz, W.J. and Mansfeld, F., 'Determination of corrosion rates by electrochemical DC and AC methods', Corrosion Science 21 (9) (1981) 647-672.

[7] Epelboin, I., Gabrielli, C., Keddam, M. and Takenouti, H., 'Alternating-current impedance measurements applied to corrosion studies and corrosion-rate determination', Electrochemical Corrosion Testing, ASTM STP 727. F. Mansfeld and U. Bertocci, Eds., American Society for Testing and Materials (1981) 150-166.

[8] Gabrielli, C., Keddam, M., Takenouti, H., Vu Quang Kinh and Bourelier, F., 'The relationship between the impedance of corroding electrode and its polarization resistance determined by a linear voltage sweep technique', Electrochimica Acta 24 (1979) 61-65.

[9] McDonald, D.D. and McKubre, M.C.H., 'Electrochemical Impedance Techniques in corrosion science', Electrochemical Corrosion Testing ASTM STP 727 - F. Mansfeld and U. Bertocci Eds. (1981) 110-149.

[10] González, J.A. and Andrade, C., 'Effect of carbonation, chlorides an relative ambient humidity on the corrosion of galvanized rebars embeded in concrete', British Corrosion Journal 17 (1) (1982) 21-28.

[11] Gouda, V.K., Shater, M.A. and Mikhail, R. Sh., 'Hardened portland blast-furnace slag cement pastes, II. The corrosion behaviour of steel reinforcement', Cement and Concrete Research 5 (1975) 1-13.

[12] Glass, G.K., Page, C.L. and Short, N.R., 'Factors affecting the corrosion rate steel in carbonated mortars', Corrosion Science 32 (12) (1991) 1283-1294.

[13] Hardon, R.G., Lambert, P. and Page, C.L., 'Relationship between electrochemical noise and corrosion rate of steel in salt contaminated concrete', British Corrosion Journal 23 (4) (1988) 225-228.

[14] Lambert, P., Page, C.L. and Vassie, P.R.W., 'Investigations of reinforcement corrosion. 2. Electrochemical monitoring of steel in chloride-contaminated concrete', Materials and Structures/Matériaux et Constructions 24 (1991) 351-358.

[15] Polder, R, Tondi, A. and Cigna, R., 'Concrete resistivity and corrosion rate of reinforcement', TNO report 93-BT-r0170, TNO Delft (1993).

[16] Pollet, V. and Raharinaivo, A., 'Assessment of damage by corrosion: Techniques for predicting the extension of rebar corrosion', International Symposium on Bridge Engineering and Management in Asian countries, PIARC, Jakarta (Indonesia) 10-13 September (1996). 
[17] Raharinaivo, A.L. and Carpio, J.J., 'The steeping down the current method: a new corrosion control for cathodic protection of steel', NACE Conference Corrosion '92, Nashville, Paper 228, (1992) 9.

[18] Dhouibi-Hachani, L, Raharinaivo, A., Triki, E. and Fiaud, C., 'Assessing the corrosion of rebars in concrete deteriorated by sulfates and carbonation', Int. Conference on Corrosion and Corrosion Protection of steel in Concrete. Ed. R.N. Swamy, Sheffield, July (1994) 258-267.

[19] Berke, N.S., Shen, D.F. and Sundberg, K.M., 'Comparison of the polarization resistance technique to the macrocell corrosion technique', Corrosion Rates of steel in Concrete, ASTM-1065, N. Berke, V. Chacker and D. Whiting Eds. (1990)38-51.

[20] Hope, B.B. and Ip, A.K.C., 'Corrosion of steel in concrete made with slag cement', ACI Materials Journal (Nov.-Dec. 1987) 525-531.

[21] Hansson, C.M., 'Comments on electrochemical measurements of the rate of corrosion of steel in concrete', Cement \& Concrete Res. 14 (1984) 574-584.

[22] Gulikers, J., 'Numerical simulation of corrosion rate determination by linear polarization', Rilem PRO 18, Workshop on Measurement and interpretation of on-site corrosion rate (Mesina), C. Andrade, C. Alonso, J. Fullea, J. Polimón and J. Rodríguez Eds., Madrid, Feb. (1999).

[23] Pedeferri, P., 'Corrosion and Protection of Metallic Materials', Librería Politécnico de Milano, Italy (1978) (only in Italian).

[24] González, J.A., Molina, A., Escudero, M.L. and Andrade, C., 'Errors in the electrochemical evaluation of very small corrosion rates. Part I. Polarization resistance method applied to corrosion of steel in concrete', Corrosion Science (UK) 25 (1985) 917-930.

[25] Glass, G.K., Page, C.L., Short, N.R. and Yu, S.W., 'An investigation of galvanostatic transient methods used to monitor the corrosion rate of steel in concrete', Corrosion Science 35 (5-8) (1993) 1585-1592.

[26] Newton, C.J. and Sykes, J.M., 'A galvanostatic pulse technique for investigation of steel corrosion in concrete', Corrosion Science 28 (1988) 1051-1074.

[27] Pollet, V., Grimaldi, G. and Raharinaivo, A., 'Corrosion rate of steel in carbonated concrete measured with polarization resistance method and a new transient technique', Paper IOR14, EUROCORR'96, Nice, France 24-27 Sept. (1996).

[28] Elsener, B., Klinhoffer, O., Frolund, T., Rislund, E., Schiegg, Y. and Böhni, H., 'Assessment of reinforcement corrosion by means of glavanostatic pulse technique', Int. Conference on Repair of Concrete Structures, Svolvær, Norway, Edited by A. Blackvoll, May (1997) 391-400.

[29] Feliú, S., González, J.A., Andrade, C. and Feliú, V., 'The determination of the corrosion rate of steel in concrete by a non-stationary method', Corrosion Science 26 (1986) 961970.

[30] Hladky, K., Callow, L.M. and Dawson, J., 'Corrosion rates from impedance measurements: an introduction', British Corrosion J. 15 (1) (1980) 20-25.

[31] Wenger, F., Galland, J., Lemoine, L., 'Méthode de contrôle de la corrosion des armatures de béton en milieu marin', International Symposium on Behaviour of offshore concrete structures, Brest, France, October (1980).

[32] Andrade, C. and Castelo, V., 'Practical measurement of the A.C. Impedance of steel bars embedded on concrete by means of a Spectrum Analyzer, Fast Fourier Transform', British Corrosion Journal (UK) 19 (1984) 93-100.

[33] Sagüés, A., 'Electrochemical impedance of corrosion macrocells on reinforcing steel in concrete', NACE Corrosion 90, Las Vegas, USA, Paper 132 (1990).

[34] Sagüés, A.A., 'Evaluation of corrosion rate by electrochemical impedance in a system with multiple polarization effects', Corrosion 89, New Orleans (USA), paper 25, April 17-21, 1989.

[35] Andrade C., Soler L. and Nóvoa, X.R., 'Advances in electrochemical impedance measurements in reinforced concrete', $5^{\text {th }}$ Intern. Symposium on electrochemical methods in Corrosion Research, EMCR'94, Sesimbra, Portugal, Sept. 1994.

[36] Epelboin, I., Gabrielli, C., Keddam, M. and Takenouti, H., 'Alternating-current impedance measurements applied to corrosion studies and corrosion rate determinations', ASTM STP 727 "Electrochemical Corrosion Testing", F. Mansfeld and U. Bertocci, Eds., American Society for Testing and Materials (1981) 150-166.

[37] Hachani, L., Carpio, J., Fiaud, C., Raharinaivo, A. and Triki, E., 'Steel corrosion in concretes deteriorated by chlorides and sulphates: electrochemical study using impedance spectrometry and stepping down the current method, Cement and Concrete Research 22 (1992) 55-66.

[38] Feliú, S., Galvan J.C., Feliú Jr., S., Bastidas, J.M., Simancas, J., Morcillo, M. and Almeida, E.M., 'An electrochemical impedance study of the behaviour of some pretreatments applied to rusted steel surfaces', Corrosion Science 35 (5-8) (1993) 1351-1358.

[39] Mansfeld, F., 'Recording and analysis of AC impedance data for corrosion studies. I. Background and methods of analysis', Corrosion (NACE) 36 (5), Mayo (1981).

[40] Elsener, B., Hug, A., Bürchler, D. and Böhni, H., 'Evaluation of localized corosion of steel in concrete by galvanostatic pulse technique', Conference on "Corrosion of Reinforcement in Concrete Construction", C.L. Page, P.B. Bamforth and J.L. Figg Eds. SCI, Cambridge (1996) 264-272.

[41] González, J.A., Andrade, C., Alonso, C. and Feliú, S., 'Comparison of rates of general corrosion and maximum pitting penetration on concrete embedded steel reinforcements', Cement \& Concrete Research 25 (2) (1995) 257-264.

[42] Andrade, C., Alonso, C. and González, J.A., 'An initial effort to use corrosion rates measurements for estimating rebar durability', Corrosion Rates of Steel in Concrete ASTM STP-1065, N. Berke, V. Chacker and D. Whiting Eds. (1990) 29-37.

[43] Mansfeld, F., 'The relationship between galvanic current and dissolution rates', Corrosion (NACE) 29 (10) (1973) 403-405.

[44] Andrade, C., Maribona, I.R., Feliú, S., González, J.A. and Feliú Jr., S., 'The effect of macrocells between active and passive areas of steel reinforcements', Corrosion Science 33 (2) (1992) 237-249.

[45] Andrade, C., Merino, P., Nóvoa, X.R., Pérez, M.C., M.C. and Soler, L., 'Passivation of reinforcing steel in concrete', Materials Science Forum 192-194 (1995) 891-898.

[46] Andrade, C., Bolzoni, F., Cabeza, M., Nóvoa, X.R. and Pérez, M.C., 'Measurement of steel corrosion in concrete by electrochemical techniques: influence of the redox processes in oxide scales', in 'Electrochemical Approach to Selected Corrosion and Corrosion Control Studies, European Federation of Corrosion Pub., no. 28, P.L. Bonora and F. Deflorian Eds., The Institute of Materials, London, UK, Cap. 25, (2000) 332-343.

[47] Andrade, C., Keddam, M., Nóvoa, X.R., Pérez, M.C. Rangel, M.C. and Takenouti, H., 'Electrochemical behaviour of steel rebars in concrete: influence of environmental factors and cement chemistry', Electrochimica Acta 46 (24-25) (2001) 3905-3912.

[48] Alonso, C., Andrade, C. Izquierdo, M., Nóvoa, X.R. and Pérez, M.C., 'Effect of protective oxide scales in the macrogalvanic behaviour of concrete reinforcements', Corrosion Science 40 (8) (1998) 1379-1389.

[49] Feliú, S., González, J.A., Andrade, C. and Feliú, V., 'Determining polarization resistance in reinforced concrete slabs', Corrosion Science 29 (1) (1989)105-113. 
[50] Seghal, A., Kho, Y.T., Osseo-Asare, K. and Pickering, H.W., 'Comparison of corrosion rate-measuring devices for determining corrosion rate of steel in concrete systems', Corrosion Engineering 48 (1992) 871-880.

[51] Andrade, C. and Alonso, C., 'Corrosion rate monitoring in the laboratory and on-site', Construction and Building Materials 10 (5) (1996) 315-328.

[52] Elsener, B. and Böhni, H., 'Galvanostatic pulse measurements. Rapid on-site corrosion monitoring', Int. Conference on Corrosion and Corrosion Protection of steel in Concrete, Sheffield, UK, Ed. R.N. Swamy, July (1994) 236-246.

[53] Mietz, J. and Isecke, B., 'Electrochemical potential monitoring on reinforced concrete structures using anodic pulse techniques', Conference on 'Non-destructive Testing in Civil Engineering', H. Bungey Ed., The British Institute of NDT, 2 (1993) 567.

[54] Feliú, S., González, J.A. and Andrade, C., 'Multipleelectrode method for estimating the polarization resistance in large structures', Journal of Applied Electrochemistry $\mathbf{2 6}$ (1996) 305-309.

[55] Andrade, C., Sarria, J. and Alonso, C., 'Statistical study on simultaneous monitoring of rebar corrosion rate and internal relative humidity in concrete structures exposed to the atmosphere', Conference on Corrosion of Reinforcement in Concrete Constructio, C.L. Page, P.B. Bamforth and J.L. Figg Eds. SCI, Cambridge (1996) 233-242.

[56] Tuutti, K., 'Corrosion of steel in concrete', Swedish Cement and Concrete Research Institute (CBI) No. 4-82, Stockholm (1982).

[57] Andrade, C. and Alonso, C., 'Values of corrosion rate of steel in concrete in order to predict service life of concrete structures', ASTM STP-1194 'Application of accelerated corrosion tests to service life prediction of materials', G. Cragnolino and U. Sridhan Eds. (1994) 282-295.

[58] Alonso, C., Andrade, C., González, J.A., 'Relation between concrete resistivity and corrosion rate of the reinforcements in carbonated mortar made with several cement types', Cement and Concrete Res. 18 (1988) 687-698.

[59] Andrade, C., Sarria, J. and Alonso, C., 'Relation between climate and corrosion rate', Workshop on Measurement and Interpretation of on-site corrosion rates, MESINA, RILEM PRO 18, C. Andrade, C. Alonso, J. Fullea, J. Polimon and J. Rodríguez, Eds., RILEM Pub., Madrid (Feb. 1999) 123-141.
[60] Andrade, C., Sarria, J. and Alonso, C., 'Relative humidity in the interior of concrete exposed to natural and artificial weathering', Cement and Concrete Research 29 (1999) 1249-1259.

[61] Andrade, C. and Alonso, C., 'On-site measurements of corrosion rate of reinforcements', Construction and Building Materials 15 (2001) 141-145.

[62] Andrade, C., Fullea, J. and Alonso, C., 'The use of the graph corrosion rate- resistivity in the measurement of the corrosion current', Workshop on Measurement and Interpretation of OnSite Corrosion Rates, MESINA, RILEM PRO 18, C. Andrade, C. Alonso, J. Fullea, J. Polimon and J. Rodríguez, Eds., RILEM Pub., Madrid (Feb. 1999) 157-165.

[63] Andrade, C., Alonso, C., González, J.A. and Rodríguez, J., 'Remaining service life of corroded structures', Proceedings of IABSE Symposium on Durability of Structures, Lisbon, September 1989, 359-363

[64] Rodríguez, J., Aragoncillo, J., Andrade, C. and Izquierdo, D., 'Manual for assessing corrosion- affected concrete structures', CONTECVET IN30902I, www.ietcc.csic.es/public_elec/Formulario_Contecvet.html.

[65] Rodríguez, J., Ortega, L.M. and Casal, J., 'Corrosion of reinforcing bars and service life of reinforced concrete structures: corrosion and bond deterioration', International Conference on Concrete Across Borders, Odense (Denmark) Vol. 1 (1994) 215-226.

[66] Rodríguez, J., Ortega, L.M., Aragoncillo, J., Izquierdo, D. and Andrade, C., 'Structural assessment for residual life calculation of concrete structures affected by reinforcement corrosion', Int. RILEM Workshop on Life Prediction and aging management of concrete structures, D. Naus Ed., Rilem Pub., Cannes, France (October 2000) 97-111.

[67] Rodríguez, J., Ortega, L.M., Casal J. and Díez, J.M., 'Corrosion of reinforcement and service life of concrete structures', in 'Durability of Building Materials and components', Vol. I, C. Sjöström Ed., E\&FN Spon Pub., London (1996) 117-126.

[68] Rodríguez, J., Ortega, L.M., Casal, J. and Díez, J.M., 'Assessing structural conditions of concrete structures with corroded reinforcements', Conference on Concrete Repair, Rehabilitation and Protection, Dundee, U.K., R.K. Dhir and M.R. Jones Eds., E\&FN Spon Pub., London (June 1996) 65-77. 